\title{
Deformation and internal flow of a chondrule-precursor molten sphere in a shocked nebular gas
}

\author{
Masayuki Uesugi ${ }^{1}$, Minoru Sekiya ${ }^{2}$, and Taishi Nakamoto ${ }^{3}$ \\ ${ }^{1}$ Department of Earth and Planetary Sciences, Graduate School of Sciences, 33 Kyushu University, \\ Hakozaki, Fukuoka 812-8581, Japan \\ ${ }^{2}$ Department of Earth and Planetary Sciences, Faculty of Sciences, 33 Kyushu University, \\ Hakozaki, Fukuoka 812-8581, Japan \\ ${ }^{3}$ Center for Computational Physics, University of Tsukuba, \\ Tsukuba, Ibaraki 305-8577, Japan
}

(Received March 18, 2003; Revised August 18, 2003; Accepted September 3, 2003)

\begin{abstract}
Chondrule formation due to a nebular shock wave heating is considered. We calculate the apparent gravitational acceleration, internal flow, and deformation of a chondrule precursor molten sphere in the shocked nebular gas. The gravitational acceleration and the internal flow are caused by momentum flux of gas molecules incident on the surface of the sphere. The gravitational acceleration just behind the shock wave is 1.1 to 330 times the terrestrial one. The velocity of the internal flow reaches around $0.1 \mathrm{~m} \mathrm{~s}^{-1}$ for the pre-shock nebular gas density and the shock wave velocity are $10^{-6} \mathrm{~kg} \mathrm{~m}^{-3}$ and $8.7 \mathrm{~km} \mathrm{~s}^{-1}$, respectively, and then chondrule melt is stirred well by the flow. As a consequence, if there is oxygen heterogeneity in the precursor particle, it must be homogenized by the high speed circulative flow in the molten sphere within a few seconds. The momentum flux also deforms the sphere. The variation of the radius of the molten sphere due to the deformation is less than $1 \%$ of the original radius for $\mathrm{mm}$-sized sphere when the sphere re-solidifies. Because we used the hydrodynamic solution with the linear approximation, the applicability of our result of the internal flow is restricted to some region of the parameter space of the shock velocity, the nebular gas density, radius and viscosity of chondrule melt sphere. For larger values of those parameters than typical ones, nonlinear calculations are needed, which is left for future works.
\end{abstract}

Key words: Meteorites, solar nebula, shock wave.

\section{Introduction}

Chondrules are igneous submillimeter-sized solid spheres of ferromagnesian silicate in chondritic meteorites. It is considered that they formed from dust aggregates through several heating events: an intense heating in a relatively cool environment $(<650 \mathrm{~K})$ melts the chondrule precursor particles and subsequent re-solidification by rapid cooling in the solar nebula forms spherical chondrules (e.g., Jones et al., 2000a). The chondrule formation process is one of the most important issues in the planetary science that should be addressed, because we can obtain plenty of information of the protoplanetary nebula environment and planetary formation processes through the investigation of the formation processes of chondrules.

Although many kinds of detailed analyses of chondrules have been performed, their origin is still unknown. After the first proposal of the chondrule formation model by Sorby (1877), many models have been proposed so far; however, none of them has won the major acceptance. They include bipolar wind (Watanabe, 1994; Liffman and Brown, 1996; Shu et al., 1996, 1997, 2001), lightning (Horanyi and Robertson, 1996; Desch and Cuzzi, 2000), meteor ablation (Liffman, 1992), and shock wave heating (e.g. Wood, 1984; Hood

Copy right(c) The Society of Geomagnetism and Earth, Planetary and Space Sciences (SGEPSS); The Seismological Society of Japan; The Volcanological Society of Japan; The Geodetic Society of Japan; The Japanese Society for Planetary Sciences. and Horanyi, 1991, 1993; Iida et al., 2001; Desch and Connolly, 2002; Ciesla and Hood, 2002). Discussions on these models are given in some review papers (Boss, 1996; Jones et al., 2000a).

The shock wave model is one of the most probable models of chondrule formation (Boss, 1996; Jones et al., 2000a). A continual accretion shock on the surface of the protoplanetary disk (Wood, 1984; Ruzmaikina and Ip, 1994), clumpy accretion shocks (Boss and Graham, 1993; Hood and Kring, 1996; Tanaka et al., 1998), a spiral density wave or mass concentrations in a gravitationally unstable nebula (Wood, 1996; Boss, 2000), and a bow shock generated by an eccentric planetesimal moving with a hypersonic velocity through the protoplanetary nebula (Hood, 1998; Weidenschilling et al., 1998), are possible in the protoplanetary disk. Chondruleprecursor dust particles are heated by those shock waves (Fig. 1). When nebular gas and dust particles cross the shock front, the nebular gas is decelerated abruptly by the gas pressure, while the precursor particle velocities are conserved. Thus, gas and precursor particles can have large relative velocities behind the shock front. The temperature of the precursor particles increase after crossing the shock front by the heating due to collisions with the gas molecules (the gas drag heating and the thermal interaction). If the heating is enough, the particles melt (Hood and Horanyi, 1991, 1993; Iida et al., 2001; Desch and Connolly, 2002; Ciesla and Hood, 2002). Since the gas pressure in the post-shock 


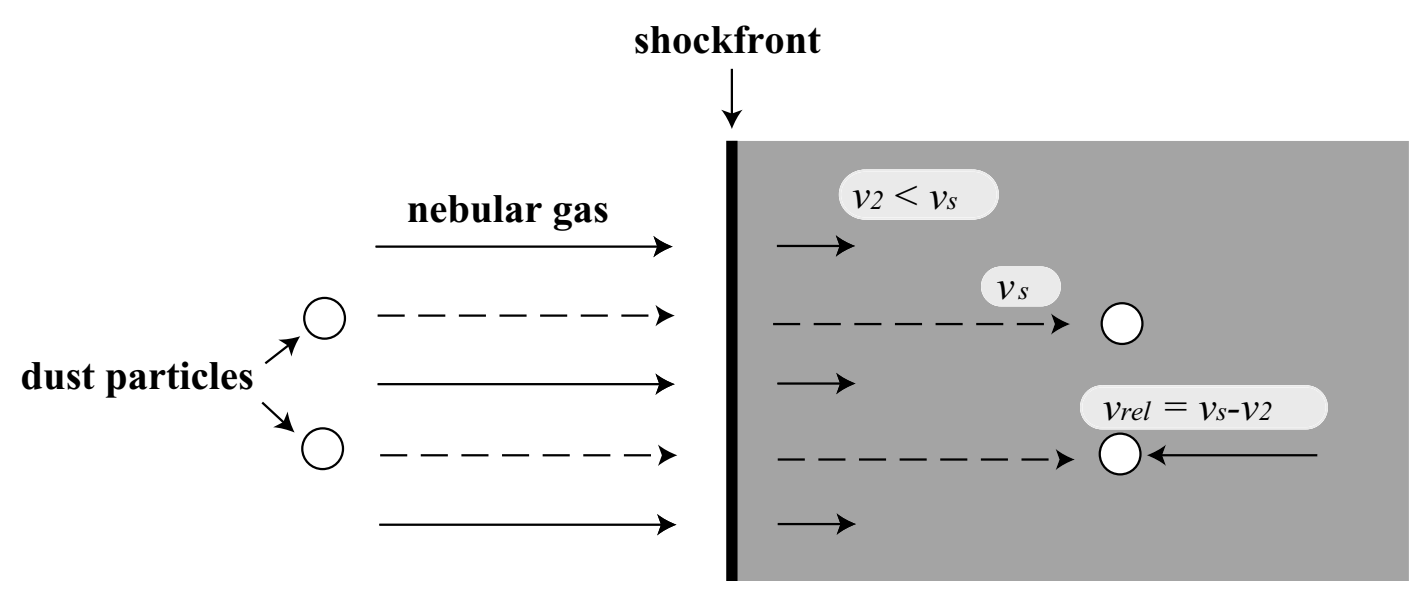

Region 1

Region 2

Fig. 1. Schematic illustration of the shock wave heating model. Solid and broken arrows represent nebular gas velocity and dust particle velocity, respectively. The gas and dust before passing the shock wave front have the same velocity $v_{\mathrm{s}}$. The gas velocity is reduced to $v_{2}$ after passing the shock front; on the other hand, the dust particle just behind the shock front conserves the velocity $v_{\mathrm{s}}$. Thus, the relative velocity between the nebular gas and dust particle $v_{\text {rel }}=v_{\mathrm{s}}-v_{2}$ occurs in the post-shock region (Region2). Dust particles entering the post shock region are heated by the gas drag and irradiation from shock-heated gas and other dust particles.

region is high enough, the molten particles can avoid boiling and hold the stable liquid state (Miura et al., 2002). If a particle is heated more and the heating is too much, the particle evaporates. On the other hand, the particle loses the energy through radiation, the thermal interaction with gas molecules, and the evaporation of dust particle. As the gas drag decelerates the particle relative motion and the heating rate diminishes, the temperature of the particle decreases. At or below the melting temperature the particle re-solidifies and forms a chondrule.

In general, molten particles in the shocked nebular gas have certain amount of relative velocity to the gas and are exposed to the momentum flux of the gas flow (Iida et al., 2001; Miura et al., 2002). The momentum flux induces the deformation and the internal flow of the molten particle (Sekiya et al., 2003). If the momentum flux is too strong, the molten particle is expected to be destructed (Susa and Nakamoto, 2002). The deformation, the internal flow, and the destruction of the molten particles can have great influence on the final products, i.e., chondrules, and there may be some imprints of these phenomena in chondrules. If we can find those imprints, they can give us great information on the chondrule formation processes. However, the nature of those phenomena has not been investigated in detail yet. To what extent is the molten particle deformed? What extent of deformation is imprinted on the chondrule? Is the internal structure homogenized by the internal flow? What kind of shocks can produce such internal flows? These questions should be addressed to reveal the nature of the heating events that formed chondrules.

Sekiya et al. (2003) examined the deformation and the internal flow of a molten particle induced by the hypersonic gas flow. They solved the linearized hydrodynamic equations and obtained a steady solution. Although they obtained the analytic solution and found that the molten particle is deformed and the internal flow is induced by the external gas flow, they did not investigate the relationship between the characteristics of the shock and the features of observed chondrules in detail. In order to reveal the nature of the chondrule-forming heating events, it is indispensable to compare the theoretical predictions with observed chondrules. Here, we explore the characteristics of the solution obtained by Sekiya et al. (2003). The degree of the deformation and the internal flow depend on the physical properties of the external gas flow and the material that comprises the chondrule precursor particle. By clarifying the feature of the analytic solution and comparing the results with observed chondrules, it is expected to reveal the nature of the chondrule-forming heating events. Unfortunately, we have not found any keys of observational evidences for or against the shock model yet, our study will provide new viewpoints to the observation of chondrules and is expected to be used in future to judge the validity of the shock wave model.

This paper is organized as follows. In Section 2, physical properties of molten particles and the shocked gas are briefly described. And also, by giving concrete values of physical parameters, the degree of the deformation and the internal flow are examined in the section. In Section 3, the validity of the linear approximation employed by Sekiya et al. (2003) is discussed. Conclusions are given in Section 4.

\section{Internal Flow and Surface Deformation of a Chondrule-Precursor Molten Sphere}

In the shocked nebular gas, momentum flux of the gas flow exerts force on the surface of molten dust particle, and the deceleration of the dust particle causes an apparent gravity. We use an analytic solution of the flow in a molten sphere moving through the rarefied gas by Sekiya et al. (2003, see Appendix A) to obtain the internal flow and the surface deformation of the chondrule-precursor molten sphere. Sekiya et al. (2003) assumed that molten sphere is isothermal and internal flow is steady, and the linear approximation is applied to the hydrodynamic equations. In Subsections 2.1 and 2.2, the physical properties of chondrule-precursor molten sphere 


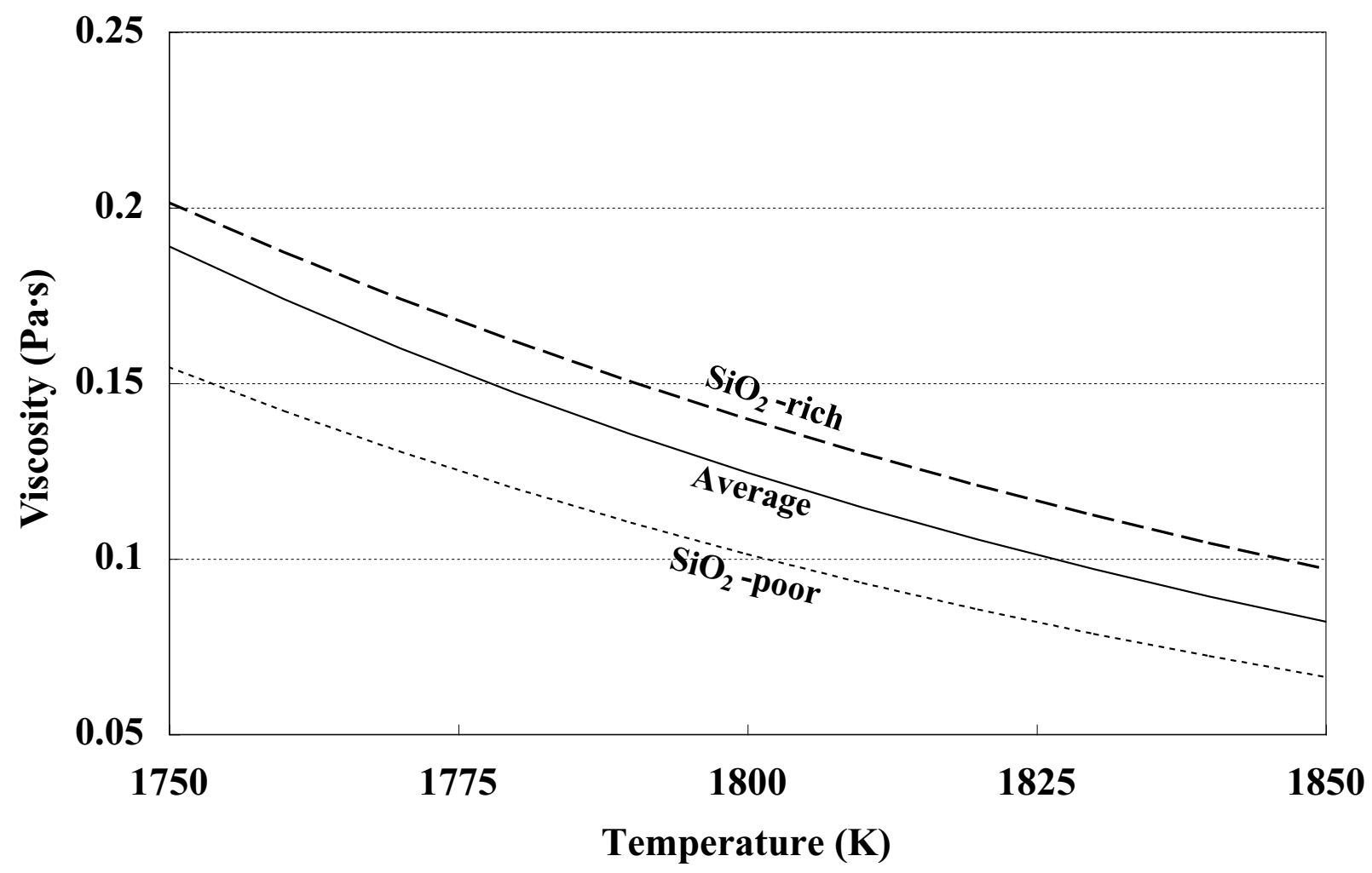

Fig. 2. Viscosities of silicate melt as functions of the temperature. The viscosities with the average composition, the composition A, and the composition $\mathrm{B}$ in Table 1 are denoted by solid, dotted, and dashed curves, respectively.

and shocked nebular gas are described, respectively. In Subsection 2.3, we give a model of the chondrule-precursor molten sphere, results of calculations, and discussions about them.

\subsection{Physical properties of chondrule melt}

Here we describe physical properties, i.e., the density, the viscosity, the radius, and the surface tension, of a chondruleprecursor molten sphere.

Kuebler and McSween (1999) summarized the density and the diameter of chondrules in ordinary chondrites. According to their results, the mean density and the diameter of chondrules are $3.4 \times 10^{3} \mathrm{~kg} \mathrm{~m}^{-3}$ and $0.59 \pm 0.25 \mathrm{~mm}$, respectively. Thus, we take the density $\rho_{s}=3.4 \times 10^{3} \mathrm{~kg} \mathrm{~m}^{-3}$ and the radius $r_{\mathrm{s} 0}=0.3 \mathrm{~mm}$ as the typical value, and cases with $r_{\mathrm{s} 0}=0.17$ and $0.42 \mathrm{~mm}$ are also examined for comparison.

The viscosity $\eta$ of molten silicate strongly depends on the temperature and the chemical composition, especially the fraction of $\mathrm{SiO}_{2}$. A chondrule formed from a sphere which was melted nearly completely is expected to have a characteristic structure that composed of a set of parallel platy olivine crystals, and is called BO type chondrule (Gooding and Keil, 1981). Table 1 shows the average composition of BO type chondrules in ordinary chondrites, and also model compositions $\mathrm{A}$ and $\mathrm{B}$ which correspond to $\mathrm{SiO}_{2}$ poor and rich compositions with the standard deviation, respectively. Viscosities calculated with a model by Bottinga and Weill (1972) for these compositions as functions of the temperature are shown in Fig. 2. The solid curve shows the viscosity of the average composition. The dotted and broken curves show the viscosities whose values are calculated from the A and B compositions in Table 1, respectively. From experi-
Table 1. Average bulk compositions of $\mathrm{BO}$ chondrules in $\mathrm{H} 3$ ordinary chondrites, and $\mathrm{SiO}_{2}$ poor and rich model compositions.

\begin{tabular}{cccc}
\hline Wt.\% oxides & $\mathrm{H} 3 *(\mathrm{sd})$ & \multicolumn{1}{c}{$A$} & $B$ \\
\hline $\mathrm{SiO}_{2}$ & $45.4(4.01)$ & 41.4 & 49.4 \\
$\mathrm{TiO}_{2}$ & $0.21(0.10)$ & 0.21 & 0.21 \\
$\mathrm{Al}_{2} \mathrm{O}_{3}$ & $5.7(2.63)$ & 5.7 & 5.7 \\
$\mathrm{FeO}$ & $14.0(3.66)$ & 15.6 & 12.9 \\
$\mathrm{MnO}$ & $0.41(0.13)$ & 0.41 & 0.41 \\
$\mathrm{MgO}$ & $28.7(5.27)$ & 31.2 & 25.8 \\
$\mathrm{CaO}$ & $2.24(1.09)$ & 2.24 & 2.24 \\
$\mathrm{Na}_{2} \mathrm{O}$ & $2.43(1.47)$ & 2.43 & 2.43 \\
$\mathrm{~K}_{2} \mathrm{O}$ & $0.45(0.72)$ & 0.45 & 0.45 \\
\hline
\end{tabular}

*1 Data from Weisberg (1987). sd=standard deviation.

mental results, it is suggested that $\mathrm{BO}$ chondrules are formed at or very slightly ( $\lesssim 10$ degrees) above their liquidus temperature (Hewins and Radomsky, 1990). So the viscosity of the sphere would be given by the value at the liquidus temperature of them. Hewins and Radomsky (1990) summarized the liquidus temperature of BO type chondrules. From figure 6 of their paper, we take the liquidus temperature as $1800 \pm 25 \mathrm{~K}$ for the BO chondrules and then the viscosity $\eta$ becomes $0.13 \pm 0.03 \mathrm{~Pa} \cdot \mathrm{s}$ at the liquidus temperature. We take $\eta=0.13 \mathrm{~Pa} \cdot \mathrm{s}$ as the typical value of the viscosity in this paper. Also, using the $\mathrm{SiO}_{2}$ rich (A) and poor (B) compositions in Table 1 and the upper and lower standard deviation of the liquidus temperature, we set upper and lower limits of 


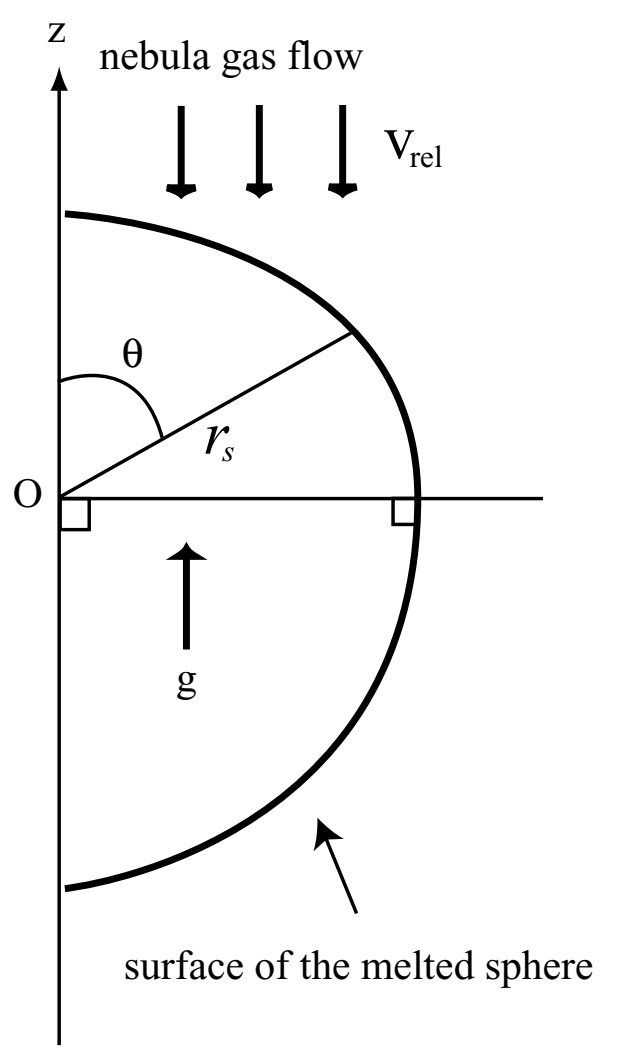

Fig. 3. Illustration of the liquid sphere in spherical coordinates. The surface is distorted by the force caused by the momentum flux of the molecular gas flow and viscosity stress of the internal flow in the liquid sphere.

the viscosity of molten chondrule as 0.17 and $0.08 \mathrm{~Pa} \cdot \mathrm{s}$ from Fig. 2, respectively.

Surface tension of the silicate melt $T_{\mathrm{s}}$ is less dependent on the temperature and the composition than the viscosity $\eta$ (King, 1951). The typical value of $T_{\mathrm{s}}$ is $0.4 \mathrm{~N} \mathrm{~m}^{-1}$ (e.g., Sekiya and Nakamura, 1996).

Since we use the solution of linearized hydrodynamic equations by Sekiya et al. (2003), our results are applicable to any values of $\rho_{\mathrm{s}}, r_{\mathrm{s} 0}, \eta$, and $T_{\mathrm{s}}$ by using scaling laws as long as the conditions for the linear approximation which will be described in Section 3 are satisfied. Note also that when our results are applied to examinations of each chondrule, radius, density, and composition of the chondrule are known values. Thus, we can obtain these physical parameters without large uncertainty, as long as the effects of the evaporation can be neglected.

\subsection{Physical conditions for the chondrule formation in the shocked nebular gas}

Thermal history of a silicate particle moving in a shocked nebular gas is affected by the gas drag, thermal interaction with gas, evaporation of the particle, and the radiation. The shock wave heating mechanism with those effects have been investigated by several authors. Iida et al. (2001) investigated in particular effects of gas chemical composition, though effects of thermal interaction and radiation from shocked gas were also taken into account. Desch and Connolly (2002) and Ciesla and Hood (2002) took into account the effects of radiation from other silicate particles. And Miura et al. (2002) mainly focused on the evaporation ef- fects. Especially, Iida et al. (2001) examined the condition of shock waves that can form chondrules by the shock wave heating mechanism for a wide range of shock velocity, the pre-shock gas density, and the initial size of precursor particles.

As will be seen in Subsection 2.3, the solution of Sekiya et al. (2003) depends on the momentum flux of the gas relative to the chondrule-precursor molten sphere,

$$
p_{\text {fm }}=\rho_{\mathrm{g}} v_{\text {rel }}^{2}
$$

where $\rho_{\mathrm{g}}$ and $v_{\text {rel }}$ are the mass density of the shocked nebular gas and the gas velocity relative to the sphere. The gas density and the relative velocity in the post shock region can be related to the gas density and the shock velocity in the preshock region using a shock wave heating model, such as the model by Iida et al. (2001). The gas density in the pre-shock region $\rho_{\mathrm{g} 0}$ is probably less than 10 times of the gas density of the minimum mass solar nebula in the Asteroid region, i.e. $\lesssim 2 \times 10^{-6} \mathrm{~kg} \mathrm{~m}^{-3}$. Also, we can naturally expect that the shock velocity $v_{\mathrm{s}}$ is lower than the Keplerian velocity in the Asteroid region, i.e. $\leq 20 \mathrm{~km} \mathrm{~s}^{-1}$. Thus, the possible range of $p_{\mathrm{fm}}$ for the chondrule formation is calculated as 20 $\leq p_{\mathrm{fm}} \leq 2500 \mathrm{~N} \mathrm{~m}^{-2}$ for $r_{\mathrm{s} 0}=0.3 \mathrm{~mm}$ (Appendix B and Fig. 10). We also calculate the possible range of $p_{\mathrm{fm}}$ for the case $r_{\mathrm{s} 0}=0.17$ and $0.42 \mathrm{~mm}$ as $20 \leq p_{\mathrm{fm}} \leq 1300 \mathrm{~N} \mathrm{~m}^{-2}$ and $20 \leq p_{\mathrm{fm}} \leq 2600 \mathrm{~N} \mathrm{~m}^{-2}$, respectively (See Figs. 11 and 12). Because we used the hydrodynamic solution with the linear approximation, the range of $p_{\mathrm{fm}}$ for which our calculation is valid is limited as we show in Section 3 (see Eq. (12)). Nonlinear calculations for the large values of $p_{\mathrm{fm}}$ are left for the future works. As for the typical values in the pre-shock region, we take $\rho_{\mathrm{g} 0}=1.2 \times 10^{-6} \mathrm{~kg} \mathrm{~m}^{-3}$ and $v_{\mathrm{s}}=8.7$ $\mathrm{km} \mathrm{s}^{-1}$. Then, we have $\rho_{\mathrm{g}}=10^{-5} \mathrm{~kg} \mathrm{~m}^{-3}, v_{\text {rel }}=7 \mathrm{~km} \mathrm{~s}^{-1}$, and $p_{\mathrm{fm}}=490 \mathrm{~N} \mathrm{~m}^{-2}$ at the moment when the dust particle begins melting.

Because our co-ordinate system is not the inertial system, an apparent gravitational acceleration $g$ is caused by the deceleration. The apparent gravity is given by

$$
g=\frac{3 p_{\mathrm{fm}}}{4 \rho_{\mathrm{s}} r_{\mathrm{s} 0}} .
$$

Using the possible range of $p_{\mathrm{fm}}$, the possible range of the apparent gravity $g$ is calculated and listed in Table 2 . We obtain $g=3.6 \times 10^{2} \mathrm{~m} \mathrm{~s}^{-2}=37 \mathrm{G}$ for the typical case, where $G$ is the gravitational acceleration on the surface of the earth.

\subsection{Model and results}

We apply the solution of Sekiya et al. (2003) to the model of chondrule-precursor molten sphere (see Appendix A). We assume that the dust particle is completely or mostly melted and isothermal, and that they have spherical shape in their unperturbed state. The model for the chondrule-precursor molten sphere is as follows. Spherical co-ordinate system $(r, \theta, \phi)$ is used with the $\theta=0$ direction (we call this direction as the z-axis) in the opposite direction to the incident gas flow (Fig. 3). The sphere is assumed to be symmetrical with respect to the z-axis (thus, $\partial / \partial \phi=0$ ) and has no azimuthal velocity $\left(v_{\phi}=0\right)$. The radius $r_{\mathrm{s}}$ of the sphere is a function of the angle $\theta$. The particle is not a sphere in the mathematical 
Table 2. Typical values and possible ranges of the obtained physical quantities*. The values written in italic letters may conatin some amount of error due to the non-linearity.

\begin{tabular}{cccc}
\hline$r_{\mathrm{s} 0}[\mathrm{~mm}]$ & 0.17 & 0.3 & 0.42 \\
\hline$g[\mathrm{G}]$ & $65(2.7,172)$ & $37(1.5,190)$ & $26(1.1,140)$ \\
$D$ & $0.21(0.0085,0.55)$ & $0.37(0.015,1.9)$ & $0.52(0.021,2.7)$ \\
$v_{\max }\left[\mathrm{m} \mathrm{s}^{-1}\right]^{\dagger}$ & $0.071(0.0022,0.3)$ & $0.13(0.0039,1.0)$ & $0.17(0.0054,1.5)$ \\
$t_{\text {mix }}[\mathrm{s}]^{\dagger}$ & $0.12(3.8,0.028)$ & $0.12(3.8,0.014)$ & $0.12(3.8,0.014)$ \\
\hline
\end{tabular}

* Calculated with the value of $p_{\mathrm{fm}}$ is typical (minimum, maximum). See also Subsection 2.2. $\dagger$ The values of viscosity $\eta$ are $0.13(0.17,0.08)[\mathrm{Pa} \cdot \mathrm{s}]$.

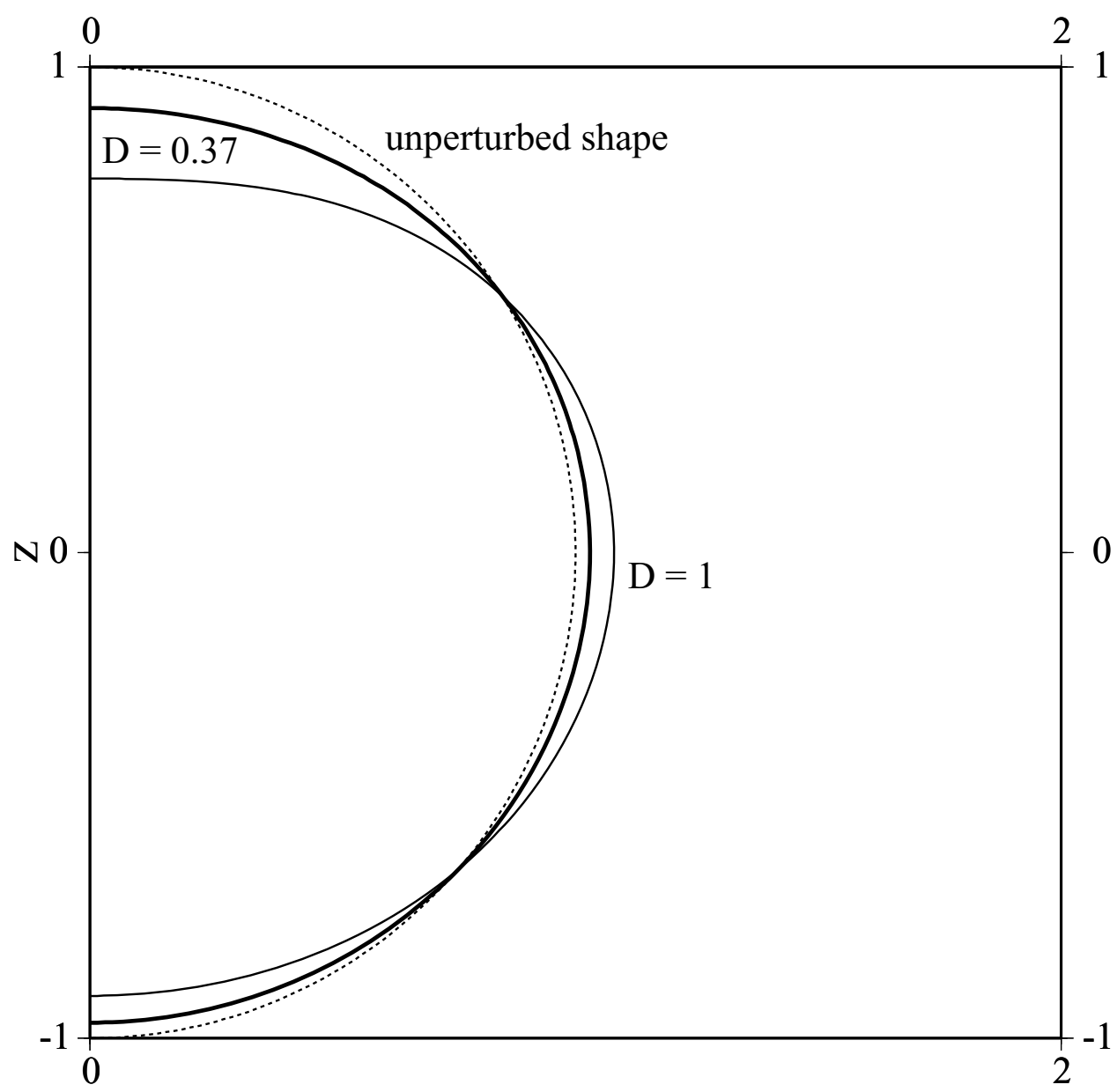

Fig. 4. The shapes of molten sphere with different values of the deformation parameter $D: D=0$ (unperturbed) with the dotted curve, $D=0.37$ (typical case) with the bold curve, and $D=1$ with the solid curve. Unit of the radius is $r_{\mathrm{s} 0}$. Positive direction of the $\mathrm{z}$-axis corresponds to $\theta=0{ }^{\circ}$.

terminology, but is slightly deformed by the momentum flux of the molecular gas. The origin of the $\mathrm{z}$-axis is situated at the point where the normal component of the surface is vertical to the z-axis. Shocked nebular gas flows with the velocity $v_{\text {rel }}$ with respect to the particle, and the momentum flux $p_{\mathrm{fm}}$ of the gas flow exerts a force on the surface of the molten sphere. When $v_{\text {rel }}$ is much larger than the sound velocity and the free molecular approximation is valid, the force only acts on the restricted range of the dust surface with $\theta<90^{\circ}$. Flow of the molten silicate sphere is driven by the $\theta$ component of the force.

Here, we calculate the deformation and the internal flow of a chondrule-precursor molten particle using the analytic solution by Sekiya et al. (2003). The deformation of the molten particle is given by (Sekiya et al., 2003, see Appendix A),

$$
r_{\mathrm{s} 1} / r_{\mathrm{s} 0}=x_{\mathrm{s}}(\theta) D
$$

where dimensionless parameter $D$ (hereafter, we call $D$ as deformation parameter) is given by

$$
D=\frac{p_{\mathrm{fm}} r_{\mathrm{s} 0}}{T_{\mathrm{s}}}=\frac{\rho_{\mathrm{g}} v_{\mathrm{rel}}^{2} r_{\mathrm{s} 0}}{T_{\mathrm{s}}} .
$$

The degree of deformation is determined by the deformation parameter $D$. The deformation parameter $D$ is the ratio of the force of momentum flux acted on the particle $\left(p_{\mathrm{fm}}\right)$ to the surface tension force $\left(T_{\mathrm{s}} / r_{\mathrm{s} 0}\right)$. The expression of the 


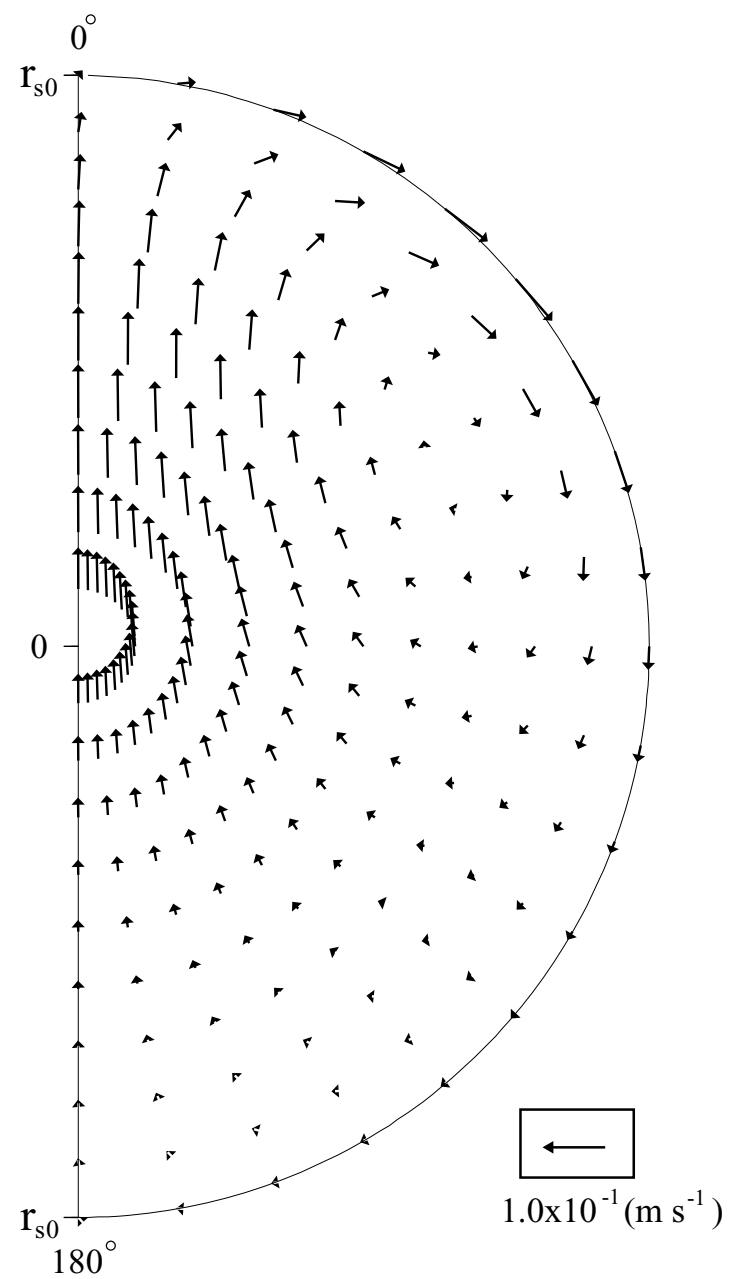

Fig. 5. The velocity vector field in the molten sphere. The scale of the velocity is shown for the case with the typical values of the parameters. The flow velocity is proportional to $v_{\text {scale }} \equiv \rho_{\mathrm{g}} v_{\text {rel }}^{2} r_{\mathrm{s} 0} / \eta$ for each point of the sphere at $\left(r / r_{\mathrm{s} 0}, \theta\right)$.

Table 3. Minimum stopping times and maximum values of the time scales*.

\begin{tabular}{cccc}
\hline$r_{\mathrm{s} 0}[\mathrm{~mm}]$ & 0.17 & 0.3 & 0.42 \\
\hline$t_{\mathrm{s}}[\mathrm{s}]$ & 5.3 & 5.3 & 7.5 \\
$t_{\mathrm{s}, \text { liquid }}[\mathrm{s}]$ & $2.4 \times 10^{-8}$ & $4.3 \times 10^{-8}$ & $6.0 \times 10^{-8}$ \\
$t_{\text {surface }}[\mathrm{s}]$ & $2.0 \times 10^{-4}$ & $4.8 \times 10^{-4}$ & $7.9 \times 10^{-4}$ \\
$t_{\text {viscosity }}[\mathrm{s}]$ & $1.2 \times 10^{-3}$ & $3.8 \times 10^{-3}$ & $7.5 \times 10^{-3}$ \\
$t_{\text {conduction }}[\mathrm{s}]$ & $2.6 \times 10^{-2}$ & $8.2 \times 10^{-2}$ & $1.6 \times 10^{-1}$ \\
$t_{\text {melt }}[\mathrm{s}]$ & 0.021 & 1.4 & 2.0 \\
\hline
\end{tabular}

* Calculated with the possible range of $\eta$, and possible range of $\rho_{\mathrm{g}}$ and $v_{\text {rel }}$ in Fig. 10, 11 and 12.

deformation parameter shows that when the force of the momentum flux is relatively large, the degree of deformation becomes large, while if the surface tension force becomes dominant, the degree becomes small. As will be discussed in Section 3 , if $D$ is larger than about 5 , it is expected that the particle should be destructed by the momentum flux. Possible range of $D$ is listed in Table 2 (see also Figs. 7 to 9). Note the maximum values of $D$ may contain some amount of error due to nonlinearity of the flow (See Section 3). Using the typical parameters $\left(p_{\mathrm{fm}}=490 \mathrm{~N} \mathrm{~m}^{-2}, r_{\mathrm{s} 0}=0.3 \mathrm{~mm}\right.$, and $T_{\mathrm{s}}=0.4 \mathrm{~N} \mathrm{~m}^{-1}$ ), we have $D=0.37$. The shape of the deformed particle is determined by a similarity function $x_{\mathrm{s}}(\theta)$.
The function $x_{\mathrm{s}}(\theta)$ depends only on $\theta$ and independent of other parameters. The value of the function $x_{\mathrm{s}}(\theta)$ is in the range $-0.23 \leq x_{\mathrm{s}}(\theta) \leq 0.079$. Radii of the particle in the z-direction $\left(\theta=0^{\circ}\right.$ and $\left.180^{\circ}\right)$ shrink, while the radius in the $\theta=90^{\circ}$ direction expands. Figure 4 shows the shape of the molten particle for three values of deformation parameter, i.e., $D=0$ (unperturbed; dotted curve), $D=0.37$ (typical case; bold curve), and $D=1$ (solid curve). For the typical case, the degrees of deformation of the dust surface $r_{\mathrm{s} 1} / r_{\mathrm{s} 0}$ are $-0.085,-0.032$, and +0.029 at the front $\left(\theta=0^{\circ}\right)$, at the rear $\left(\theta=180^{\circ}\right)$, and at the side $\left(\theta=90^{\circ}\right)$, respectively.

As seen in Eq. (4), $D$ is proportional to $r_{\mathrm{s} 0}$. So, if there 

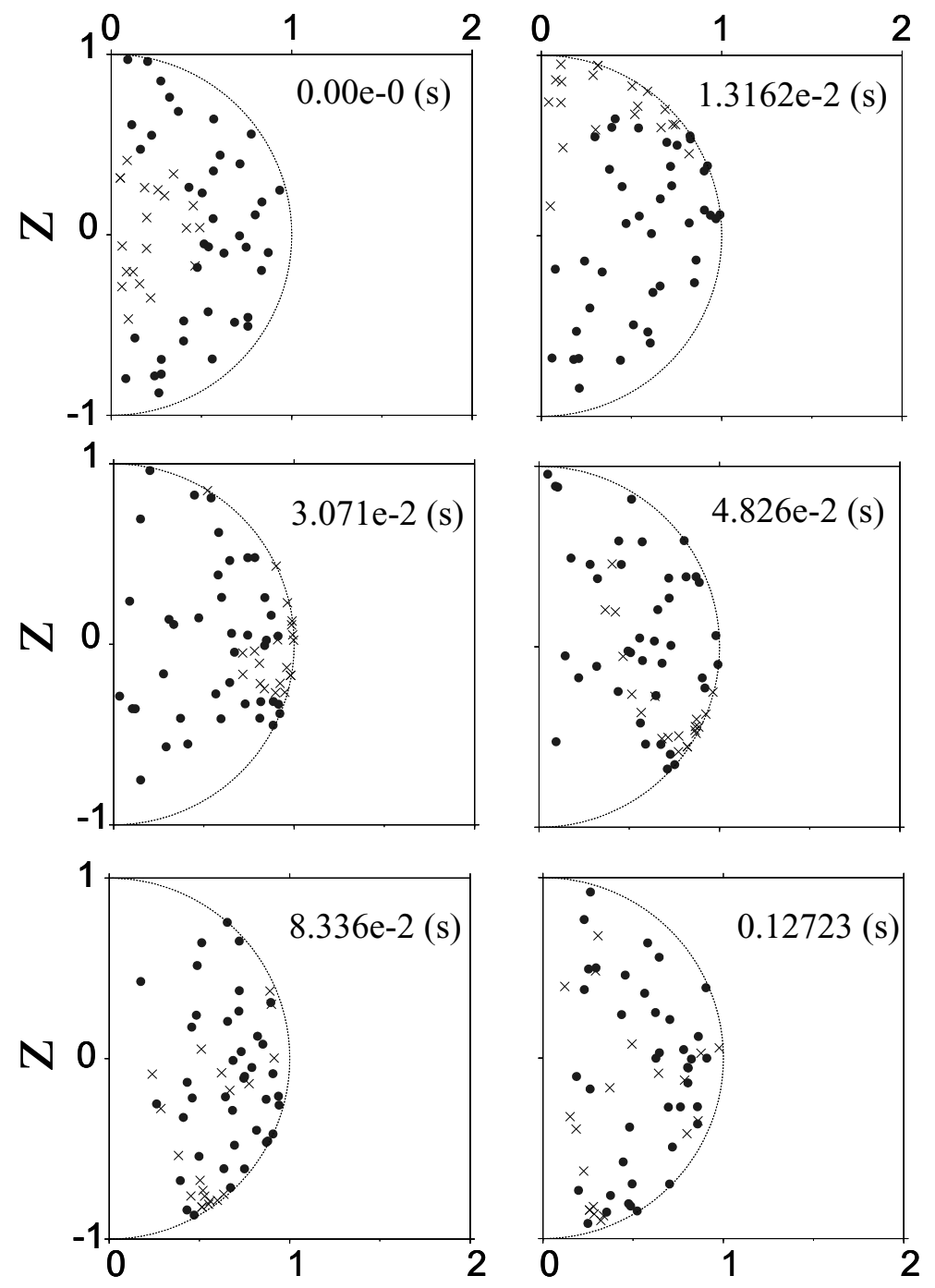

Fig. 6. Mixing of fluid elements in a molten sphere by the flow for the typical case. Inner and outer part of the sphere before the mixing are represented by the closed bullet $(\bullet)$ and cross $(\times)$ symbols, respectively.

were large chondrule-precursor molten particles, their deformation parameter would be large $(D \gtrsim 5)$, and it is expected that the molten particles would split into two or more pieces. Note that formula of Sekiya et al. (2003) is not applicable for such large deformation cases, since they have used the linear approximation. For those cases, we must perform nonlinear calculations, but they are left for the future work. It has been suggested that dust size distribution converges to the present chondrule size range by the repetition of such separations (Susa and Nakamoto, 2002).

The velocity field in the molten sphere for the typical case is shown in Fig. 5. The flow velocity at a given values of $\left(r / r_{\mathrm{s} 0}, \theta\right)$ is proportional to

$$
v_{\text {scale }} \equiv p_{\mathrm{fm}} r_{\mathrm{s} 0} / \eta=\rho_{\mathrm{g}} v_{\mathrm{rel}}^{2} r_{\mathrm{s} 0} / \eta .
$$

As shown in Fig. 5, circular flow field is driven by the $\theta$ component of the momentum flux acted to the dust surface. The flow velocity has the maximum value $v_{\max }=0.11 v_{\text {scale }}$ at $\theta=47^{\circ}$ on the dust surface (Sekiya et al., 2003). The possible range of $v_{\max }$ is listed in Table 2. Because we used the hydrodynamic solution with the linear approximation, the maximum value of $v_{\max }$ may contain a certain amount of error. The applicability of our results is discussed in Section 3 . For the typical case, the maximum velocity $v_{\max }$ is $0.13 \mathrm{~m} \mathrm{~s}^{-1}$.

In Figure 6, we show the motion of fluid elements in a chondrule melt for the typical case. Symbols in Fig. 6 such as $\bullet$ and $\times$ are markers of the fluid elements. Initially, we put fluid elements with bullet symbols $(\bullet)$ in the region $r \geq 0.5 r_{\mathrm{s} 0}$ and those with the cross symbols $(\times)$ in the region $r<0.5 r_{\mathrm{s} 0}$. As time elapses, these fluid elements (symbols) move with the flow in the sphere. And the material in the sphere is well mixed within a short period $(\sim 0.12 \mathrm{~s})$.

Here, we define the time scale of the mixing as $t_{\text {mix }}$. Since $t_{\text {mix }}$ is proportional to $r_{\mathrm{s} 0} / v_{\text {scale }} \sim \eta / p_{\text {fm }}$, we have

$$
t_{\text {mix }}=0.12\left(\frac{\eta}{0.13 \mathrm{~Pa} \cdot \mathrm{s}}\right)\left(\frac{p_{\mathrm{fm}}}{490 \mathrm{~N} \mathrm{~m}^{-2}}\right)^{-1} \mathrm{~s} .
$$

If the values of $\eta$ and $p_{\mathrm{fm}}$ are different from typical ones, the time scale of mixing changes from the typical value, but flow pattern does not change because of the linearized hydrodynamic equations (Sekiya et al., 2003). Using the possible range of $p_{\mathrm{fm}}$ and $\eta$, we obtain the possible range of $t_{\text {mix }}$ as $0.014 \leq t_{\text {mix }} \leq 3.8 \mathrm{~s}$ for $r_{\mathrm{s} 0}=0.3 \mathrm{~mm}$ and $r_{\mathrm{s} 0}=0.42$ 
$\mathrm{mm}$, and $0.028 \leq t_{\text {mix }} \leq 3.8 \mathrm{~s}$ for $r_{\mathrm{s} 0}=0.17 \mathrm{~mm}$. Note again that the minimum value of $t_{\text {mix }}$ may contain a certain amount of error (see Section 3).

The time scale of the deceleration of the dust particle $t_{\mathrm{s}}$ is given by

$$
t_{\mathrm{s}}=\frac{4 r_{\mathrm{s} 0} \rho_{\mathrm{s}}}{3 \rho_{\mathrm{g}} v_{\mathrm{rel}}} .
$$

We have $t_{\mathrm{s}} \sim 20 \mathrm{~s}$ for the typical case. The ratio of $t_{\mathrm{s}}$ and $t_{\text {mix }}$ is given by

$$
\begin{aligned}
t_{\text {mix }} / t_{\mathrm{s}}= & 6.3 \times 10^{-3}\left(\frac{\eta}{0.13 \mathrm{~Pa} \cdot \mathrm{s}}\right)\left(\frac{\rho_{\mathrm{s}}}{3.4 \times 10^{3} \mathrm{~kg} \mathrm{~m}^{-3}}\right)^{-1} \\
& \cdot\left(\frac{v_{\mathrm{rel}}}{7 \mathrm{~km} \mathrm{~s}^{-1}}\right)^{-1}\left(\frac{r_{\mathrm{s} 0}}{3.0 \times 10^{-4} \mathrm{~m}}\right)^{-1}
\end{aligned}
$$

which is always much smaller than unity $(\leq 0.03)$ for the possible range of parameters. Therefore, it is highly expected that the inside of a completely molten chondrule should be homogenized.

In the shock wave formation model of chondrules, surface deformation and internal flow pattern of melt, shown in Figs. 4 and 5, are established within a quite short period of time ( $<2 \mathrm{~s}$, which is the maximum value of time scales discussed in Section 3) after the complete melting of the dust particle. Here, we consider whether the traces of the shock wave, such as the internal flow pattern and the deformation obtained above, are observable in the present chondrules or not.

After the steady state of internal flow is established, initial heterogeneity in the chondrule is stirred up and quickly homogenized by the high speed circular flow. According to observations, oxygen isotope ratio of olivine crystals in $\mathrm{BO}$ chondrules is homogeneous among olivine crystals, while that of some porphyritic chondrules is inhomogeneous (Tomoki Nakamura, private communication). Taking into account our new results obtained above, there seems a possibility that the distribution of oxygen isotope ratio is homogenized by the high velocity circulation, if they are formed by the shock wave heating. It is usually considered that the homogeneous oxygen isotope ratio distribution of the crystals in BO type chondrules is due to the diffusion of the oxygen in the molten silicate. The diffusivity of oxygen in the molten silicate material is about $10^{-8}-10^{-10} \mathrm{~m}^{2} \mathrm{~s}^{-1}$, which is much larger than that of solid silicate (Dunn, 1982), and inside of chondrule would be homogeneous in 10 to 1000 $\mathrm{s}$ after the total melting. From our results, $t_{\text {mix }}$ is at least one order of magnitude shorter than homogenization by the diffusion. So, we can expect that the circular flow is much effective than the diffusion for the internal homogenization of the chondrule for the shock wave heating.

On the other hand, if the melting of the particle is not completed enough, the viscosity in the particle should be quite large and the circular flow in the particle should be inhibited. If it is the case, the inhomogeneity in the original particle is expected to be left in incompletely melted chondrules, such as porphyritic chondrules.

Circular flow and diffusion might leave different imprints in chondrules which have heterogeneous oxygen isotope ratio distribution. If the inside of chondrules is incompletely homogenized by the diffusion, silicate material at an outer part of a chondrule would be ${ }^{16} \mathrm{O}$ poorer than that at an inner part, because it interacts more efficiently with nebular gas, which is considered to be ${ }^{16} \mathrm{O}$ poorer than precursor dust grains (Clayton, 1993). But if there is a high speed circular flow in the chondrule, the silicate material which is close to the surface at a moment would move to a part deep inside of the chondrule at the next moment. The time scale of the turnover in the sphere would be small even when the sphere does not melt completely. So, the distribution of the oxygen isotope in each crystals would have no difference. This is an interesting topic of oxygen isotopic analysis. Mapping of oxygen isotope ratio in chondrules has been done in some analyses (Hiyagon, 1997; Jones et al., 2000b), but unfortunately the number of studies is still too little to discuss quantitatively. In contrast to oxygen isotope distribution, the diffusion velocities of volatile elements, e.g. $\mathrm{Na}$ are very fast in a melted chondrule, and it is more difficult to discriminate the homogenization due to the circular flow from that by the diffusion. In both cases, the loss of the volatile elements are regulated not by the internal homogenization but by the evaporation and the reaction on the surface of melted chondrule (Tsuchiyama et al., 1981). Thus, it is unlikely that the loss of the volatile elements is accelerated by the circular flow.

As the sphere flows away from the shock front and the relative velocity $v_{\text {rel }}$ decreases, the degree of deformation decreases. Also, the particle temperature decreases because of the decrease of the heating rate. When its temperature falls below the melting temperature $T_{\text {melt }}$, the particle re-solidifies from its surface and the deformation is fixed. It is considered that the deformation of the surface at this moment is small because the relative velocity is expected to be small. Indeed, the relative velocity at the moment of the re-solidification is evaluated to be about a half or less of the maximum value (Iida et al. 2001) by assuming that re-solidification occurs at the liquidus temperature. Thus, $v_{\text {rel }} \leq 0.5 v_{\mathrm{s}}$, the degree of deformation at the front of the particle $\left(\theta=0^{\circ}\right)$ is $\lesssim 10^{-2} r_{\mathrm{s} 0}$ for the possible parameter range. It seems difficult to see the deformation of the particle due to the momentum flux in the observed chondrules. Note that the effect of nonlinearity becomes small at the moment of re-solidification. Tsuchiyama et al. (2002) performed 3-dimensional observation of the oblate shape chondrules with CT scanning. According to their results, mean aspect ratio of those chondrules is $\sim 0.9$. Those oblate shapes of chondrules are probably due to their rotation. Tsuchiyama et al. (2002) concluded that the deformation corresponds to the 50-350 rps rotation of the molten silicate droplet.

In consequence, the implication of shock wave heating might be observable in the present chondrules in some cases, but number of observations/measurements made so far is still little. The results we obtained provide a lot of viewpoints to the future observations.

\section{Applicability of the Obtained Results}

As noted in Sections 1 and 2, one of our purposes of this paper is to provide new viewpoints to observations and analyses of chondrules. In applying our results, it is necessary to confirm the following conditions. It should be noted that our 


\begin{tabular}{|c|c|c|c|c|c|c|c|c|c|c|c|c|}
\hline $\mathrm{v}_{\mathrm{S}}\left[\mathrm{km} \mathrm{s}^{-1}\right]$ & 5 & 6 & 7 & 8 & 9 & 10 & 12 & 14 & 16 & 18 & 20 & 25 \\
\hline \multicolumn{13}{|l|}{$\log \left(\rho_{\mathrm{g} 0}\left[\mathrm{~kg} \mathrm{~m}^{-3}\right]\right.$} \\
\hline-5.5 & _- & & & & & & & & & & & \\
\hline \multirow[t]{4}{*}{-5.75} & - & 0.22 & 0.55 & 1.00 & 1.61 & 2.45 & 4.94 & + & $\operatorname{Re}(\eta=0.13)$ & & & \\
\hline & & 0.57 & 1.46 & 2.63 & 4.25 & 6.47 & 13.04 & & $\operatorname{Re}(\eta=0.08)$ & & & \\
\hline & & 0.13 & 0.32 & 0.58 & 0.94 & 1.43 & 2.89 & & $\operatorname{Re}(\eta=0.17)$ & & & \\
\hline & & 0.08 & 0.21 & 0.38 & 0.61 & 0.92 & 1.86 & & D & & & \\
\hline \multirow[t]{4}{*}{-6.0} & _ & - & 0.30 & 0.56 & 0.90 & 1.36 & 2.71 & + & & & & \\
\hline & & & 0.79 & 1.47 & 2.37 & 3.58 & 7.15 & & & & & \\
\hline & & & 0.18 & 0.32 & 0.53 & 0.79 & 1.58 & & & & & \\
\hline & & & 0.11 & 0.21 & 0.34 & 0.51 & 1.02 & & & & & \\
\hline \multirow[t]{4}{*}{-6.25} & & _ & & 0.31 & 0.50 & 0.75 & 1.49 & + & & & & \\
\hline & & & $\wedge$ & 0.81 & 1.33 & 1.99 & 3.92 & & & & & \\
\hline & & & $\Delta$ & 0.18 & 0.29 & 0.44 & 0.87 & & & & & \\
\hline & & & & 0.12 & 0.19 & 0.28 & 0.56 & & & & & \\
\hline \multirow[t]{4}{*}{-6.5} & & & _ & & 0.28 & 0.42 & 0.82 & 1.39 & + & & & \\
\hline & & & & $A$ & 0.74 & 1.11 & 2.16 & 3.66 & & & & \\
\hline & & & & $\Delta$ & 0.16 & 0.25 & 0.48 & 0.81 & & & & \\
\hline & & & & & 0.11 & 0.16 & 0.31 & 0.52 & & & & \\
\hline \multirow[t]{4}{*}{-6.75} & & & & _ & & 0.24 & 0.46 & 0.75 & + & & & \\
\hline & & & & & $\wedge$ & 0.63 & 1.20 & 1.99 & & & & \\
\hline & & & & & $\Delta$ & 0.14 & 0.27 & 0.44 & & & & \\
\hline & & & & & & 0.09 & 0.17 & 0.28 & & & & \\
\hline \multirow[t]{4}{*}{-7.0} & & & & & _- & & 0.26 & 0.41 & 0.56 & & & \\
\hline & & & & & & & 0.68 & 1.09 & 1.48 & & & \\
\hline & & & & & & $\triangle$ & 0.15 & 0.24 & 0.33 & & & \\
\hline & & & & & & & 0.10 & 0.16 & 0.21 & & & \\
\hline \multirow[t]{4}{*}{-7.25} & & & & & & _- & 0.15 & 0.23 & 0.30 & & & \\
\hline & & & & & & & 0.40 & 0.62 & 0.79 & & & \\
\hline & & & & & & & 0.09 & 0.14 & 0.18 & & & \\
\hline & & & & & & & 0.06 & 0.09 & 0.11 & & & \\
\hline \multirow[t]{4}{*}{-7.5} & & & & & & _- & - & 0.14 & 0.17 & 0.13 & + & \\
\hline & & & & & & & & 0.36 & 0.44 & 0.34 & & \\
\hline & & & & & & & & 0.08 & 0.10 & 0.08 & & \\
\hline & & & & & & & & 0.05 & 0.06 & 0.05 & & \\
\hline \multirow[t]{4}{*}{-7.75} & & & & & & & - & - & 0.10 & 0.07 & 0.07 & \\
\hline & & & & & & & & & 0.27 & 0.19 & 0.19 & \\
\hline & & & & & & & & & 0.06 & 0.04 & 0.04 & \\
\hline & & & & & & & & & 0.04 & 0.03 & 0.03 & \\
\hline \multirow[t]{4}{*}{-8.0} & & & & & & & & _- & & - & 0.04 & \\
\hline & & & & & & & & & $\triangle$ & & 0.10 & \\
\hline & & & & & & & & & & & 0.02 & \\
\hline & & & & & & & & & & & 0.01 & \\
\hline-8.25 & & & & & & & & & - & - & - & \\
\hline-8.5 & & & & & & & & & & & & - \\
\hline $\mathrm{v}_{\mathrm{s}}\left[\mathrm{km} \mathrm{s}^{-1}\right]$ & 5 & 6 & 7 & 8 & 9 & 10 & 12 & 14 & 16 & 18 & 20 & 25 \\
\hline
\end{tabular}

Fig. 7. Possible range of dimensionless parameters $D$ and $R e$ for the various value shock velocity $v_{\mathrm{s}}$ and pre-shock nebular gas density $\rho_{\mathrm{g} 0}$. These values are obtained using the possible range of $p_{\mathrm{fm}}$ and $\eta$. The shaded values of Re indicate those satisfying the critical condition. As seen in the figure, the critical condition of $D$ is always satisfied. The radius of the particle is $r_{\mathrm{s} 0}=0.3 \mathrm{~mm}$.

results can only be applicable to chondrules which melted completely or mostly. Some readers may worry about the applicability of our results because the percentage of the BO chondrule is as small as 5\%. However, we can select observationally a chondrule which melted well when we apply our results to each chondrule. In the following, we check the applicability of our results to BO type chondrules.

In this paper, the internal flow is assumed to be steady. In reality, however, it might not be steady because of the gas drag deceleration. So, this assumption should be verified. If the time scales listed below (from (1) to (5)) are smaller than the stopping time, the internal flow and the surface deformation can be regarded as steady. The stopping time $t_{\mathrm{s}}$ (see Eq. (7)) is given for the super sonic flow case by

$$
\begin{aligned}
t_{\mathrm{s}}= & 19\left(\frac{r_{\mathrm{s} 0}}{3 \times 10^{-4} \mathrm{~m}}\right)\left(\frac{\rho_{\mathrm{s}}}{3.4 \times 10^{3} \mathrm{~kg} \mathrm{~m}^{-3}}\right) \\
& \cdot\left(\frac{\rho_{\mathrm{g}}}{10^{-5} \mathrm{~kg} \mathrm{~m}^{-3}}\right)^{-1}\left(\frac{v_{\mathrm{rel}}}{7 \mathrm{~km} \mathrm{~s}^{-1}}\right)^{-1} \mathrm{~s} .
\end{aligned}
$$

(1) The time scale for the sound wave in the particle, whose velocity $c_{\mathrm{s} \text {, liquid }}$ is about $7 \mathrm{~km} \mathrm{~s}^{-1}$, to cross through the dust particle radius $r_{\mathrm{s} 0}$ is,

$$
\begin{aligned}
t_{\mathrm{s}, \text { liquid }}=\frac{r_{\mathrm{s} 0}}{c_{\mathrm{s}, \text { liquid }}}= & 4.3 \times 10^{-8} \\
& \cdot\left(\frac{r_{\mathrm{s} 0}}{3 \times 10^{-4} \mathrm{~m}}\right)\left(\frac{c_{\mathrm{s}, \text { liquid }}}{7 \mathrm{~km} \mathrm{~s}^{-1}}\right)^{-1} \mathrm{~s} .
\end{aligned}
$$

(2) A period of dust surface oscillation is (Landau and Lifshitz, 1959)

$$
\begin{aligned}
t_{\text {surface }}=\left(\frac{\rho_{\mathrm{s}} r_{\mathrm{s} 0}^{3}}{T_{\mathrm{s}}}\right)^{1 / 2}= & 4.8 \times 10^{-4} \\
& \cdot\left(\frac{r_{\mathrm{s} 0}}{3 \times 10^{-4} \mathrm{~m}}\right)^{3 / 2}\left(\frac{T_{\mathrm{s}}}{0.4 \mathrm{~N} \mathrm{~m}^{-2}}\right)^{-1 / 2} \\
& \cdot\left(\frac{\rho_{\mathrm{s}}}{3.4 \times 10^{3} \mathrm{~kg} \mathrm{~m}^{-3}}\right)^{1 / 2} \mathrm{~s} .
\end{aligned}
$$

(3) The time scale of the viscous force, with which the viscous force is transmitted to the entire particle, is

$$
\begin{aligned}
t_{\mathrm{viscosity}}=\frac{r_{\mathrm{s} 0}^{2} \rho_{\mathrm{s}}}{\eta}= & 2.4 \times 10^{-3}\left(\frac{r_{\mathrm{s} 0}}{3 \times 10^{-4} \mathrm{~m}}\right)^{2} \\
& \cdot\left(\frac{\eta}{0.13 \mathrm{~Pa} \cdot \mathrm{s}}\right)^{-1}\left(\frac{\rho_{\mathrm{s}}}{3.4 \times 10^{3} \mathrm{~kg} \mathrm{~m}^{-3}}\right) \mathrm{s}
\end{aligned}
$$




\begin{tabular}{|c|c|c|c|c|c|c|c|c|c|c|c|c|}
\hline $\mathrm{v}_{\mathrm{S}}\left[\mathrm{km} \mathrm{s}^{-1}\right]$ & 5 & 6 & 7 & 8 & 9 & 10 & 12 & 14 & 16 & 18 & 20 & 25 \\
\hline \multicolumn{13}{|c|}{$\log \left(\rho_{\mathrm{g} 0}\left[\mathrm{~kg} \mathrm{~m}^{-3}\right]\right.$} \\
\hline-5.5 & - & & & & & & & & & & & \\
\hline-5.75 & - & $\triangle$ & $\begin{array}{l}1.10 \\
2.92 \\
0.65 \\
0.30\end{array}$ & $\begin{array}{l}1.99 \\
5.26 \\
1.16 \\
0.54 \\
\end{array}$ & $\begin{array}{l}3.24 \\
8.55 \\
1.89 \\
0.87 \\
\end{array}$ & $\begin{array}{c}4.92 \\
12.99 \\
2.88 \\
1.32 \\
\end{array}$ & $\begin{array}{c}10.15 \\
26.80 \\
5.94 \\
2.73 \\
\end{array}$ & + & $\begin{array}{c}\operatorname{Re}(\eta=0.13) \\
\operatorname{Re}(\eta=0.08) \\
\operatorname{Re}(\eta=0.17) \\
\mathrm{D}\end{array}$ & & & \\
\hline-6.0 & - & - & $\begin{array}{l}0.60 \\
1.58 \\
0.35 \\
0.16\end{array}$ & $\begin{array}{l}1.11 \\
2.94 \\
0.65 \\
0.30\end{array}$ & $\begin{array}{l}1.80 \\
4.76 \\
1.05 \\
0.49\end{array}$ & $\begin{array}{l}2.74 \\
7.23 \\
1.60 \\
0.74 \\
\end{array}$ & $\begin{array}{c}5.54 \\
14.64 \\
3.24 \\
1.49 \\
\end{array}$ & + & & & & \\
\hline-6.25 & & - & $\triangle$ & $\begin{array}{l}0.62 \\
1.63 \\
0.36 \\
0.17\end{array}$ & $\begin{array}{l}1.01 \\
2.66 \\
0.59 \\
0.27 \\
\end{array}$ & $\begin{array}{l}1.52 \\
4.02 \\
0.89 \\
0.41 \\
\end{array}$ & $\begin{array}{l}3.04 \\
8.03 \\
1.78 \\
0.82 \\
\end{array}$ & + & & & & \\
\hline-6.5 & & & - & $\triangle$ & $\begin{array}{l}0.57 \\
1.49 \\
0.33 \\
0.15 \\
\end{array}$ & $\begin{array}{l}0.85 \\
2.26 \\
0.50 \\
0.23 \\
\end{array}$ & $\begin{array}{l}1.67 \\
4.41 \\
0.98 \\
0.45 \\
\end{array}$ & $\begin{array}{l}2.89 \\
7.63 \\
1.69 \\
0.78\end{array}$ & + & & & \\
\hline-6.75 & & & & - & $\triangle$ & $\begin{array}{l}0.48 \\
1.28 \\
0.28 \\
0.13 \\
\end{array}$ & $\begin{array}{l}0.93 \\
2.45 \\
0.54 \\
0.25 \\
\end{array}$ & $\begin{array}{l}1.56 \\
4.11 \\
0.91 \\
0.42 \\
\end{array}$ & + & & & \\
\hline-7.0 & & & & & - & $\triangle$ & $\begin{array}{l}0.52 \\
1.38 \\
0.31 \\
0.14 \\
\end{array}$ & $\begin{array}{l}0.85 \\
2.26 \\
0.50 \\
0.23 \\
\end{array}$ & $\begin{array}{l}1.19 \\
3.13 \\
0.69 \\
0.32 \\
\end{array}$ & + & & \\
\hline-7.25 & & & & & & - & $\begin{array}{l}0.32 \\
0.83 \\
0.18 \\
0.08 \\
\end{array}$ & $\begin{array}{l}0.48 \\
1.27 \\
0.28 \\
0.13 \\
\end{array}$ & $\begin{array}{l}0.63 \\
1.67 \\
0.37 \\
0.17 \\
\end{array}$ & & & \\
\hline-7.5 & & & & & & - & - & $\begin{array}{l}0.29 \\
0.76 \\
0.17 \\
0.08\end{array}$ & $\begin{array}{l}0.35 \\
0.92 \\
0.20 \\
0.09\end{array}$ & $\begin{array}{l}0.26 \\
0.68 \\
0.15 \\
0.07\end{array}$ & + & \\
\hline-7.75 & & & & & & & - & - & $\begin{array}{l}0.22 \\
0.57 \\
0.13 \\
0.06\end{array}$ & $\begin{array}{l}0.14 \\
0.37 \\
0.08 \\
0.04\end{array}$ & $\begin{array}{l}0.14 \\
0.38 \\
0.08 \\
0.04\end{array}$ & \\
\hline-8.0 & & & & & & & & - & $\begin{array}{l}0.27 \\
0.71 \\
0.16 \\
0.07 \\
\end{array}$ & - & $\begin{array}{l}0.08 \\
0.21 \\
0.05 \\
0.02 \\
\end{array}$ & \\
\hline-8.25 & & & & & & & & & - & - & - & \\
\hline-8.5 & & & & & & & & & & & & - \\
\hline $\mathrm{v}_{\mathrm{S}}\left[\mathrm{km} \mathrm{s}^{-1}\right]$ & 5 & 6 & 7 & 8 & 9 & 10 & 12 & 14 & 16 & 18 & 20 & 25 \\
\hline
\end{tabular}

Fig. 8. Same as Fig. 7 except for $r_{\mathrm{s} 0}=0.42 \mathrm{~mm}$.

(4) The time scale of the thermal energy diffusion in the dust particle is

$$
\begin{aligned}
t_{\text {conduction }}=\frac{r_{\mathrm{s} 0}^{2}}{\kappa_{\text {therm }}}= & 8.2 \times 10^{-2}\left(\frac{r_{\mathrm{s} 0}}{3 \times 10^{-4} \mathrm{~m}}\right)^{2} \\
& \cdot\left(\frac{\kappa_{\text {therm }}}{1.1 \times 10^{-6} \mathrm{~m}^{2} \mathrm{~s}^{-1}}\right)^{-1} \mathrm{~s},
\end{aligned}
$$

where $\kappa_{\text {therm }}=1.1 \times 10^{-6} \mathrm{~m}^{2} \mathrm{~s}^{-1}$ is the thermometric diffusivity of the silicate material (e.g., Stacey, 1992; Podolak et al., 1993). And

(5) the time scale of the total melting of the particle is

$$
\begin{aligned}
t_{\text {melt }}=\frac{\rho_{\mathrm{s}} r_{\mathrm{s} 0} L_{\text {melt }}}{p_{\mathrm{fm}} v_{\text {rel }}}= & 0.13\left(\frac{r_{\mathrm{s} 0}}{3 \times 10^{-4} \mathrm{~m}}\right) \\
& \cdot\left(\frac{\rho_{\mathrm{s}}}{3.4 \times 10^{3} \mathrm{~kg} \mathrm{~m}^{-3}}\right)\left(\frac{L_{\text {melt }}}{4.5 \times 10^{5} \mathrm{~J} \mathrm{~kg}^{-1}}\right) \\
& \cdot\left(\frac{p_{\mathrm{fm}}}{490 \mathrm{~N} \mathrm{~m}^{-2}}\right)^{-1}\left(\frac{v_{\mathrm{rel}}}{7 \mathrm{~km} \mathrm{~s}^{-1}}\right)^{-1} \mathrm{~s},
\end{aligned}
$$

where $L_{\text {melt }}=4.5 \times 10^{5} \mathrm{~J} \mathrm{~kg}^{-1}$ is the latent heat of melting silicate material (Hood and Horanyi, 1991). All the time scales are normalized by the typical values. The values of these time scales are listed in Table 3 for possible parameter ranges. As seen in Table 3, all the time scales from (1) to
(5) are smaller than the minimum stopping time for possible parameter ranges. Therefore, although the flow in the dust particle changes with the decrease of the relative velocity, we can use approximately the steady solution by Sekiya et al. (2003) to obtain the flow in the chondrule melt at each moment using the value of $v_{\text {rel }}$ appropriate for the moment.

In Sekiya et al. (2003), the linear approximation for the hydrodynamic equations as well as for the equation of the surface curvature is used. This approximation is valid only when the following conditions are satisfied:

$$
R e=\frac{v_{\max } \rho_{\mathrm{s}} r_{\mathrm{s} 0}}{\eta}=0.11 \frac{p_{\mathrm{fm}} \rho_{\mathrm{s}} r_{\mathrm{s} 0}^{2}}{\eta^{2}}<<1,
$$

and

$$
\left|\frac{r_{\mathrm{s} 1}}{r_{\mathrm{s} 0}}\right|=\left|x_{\mathrm{s}}\right| D<<1
$$

Dimensionless parameters $R e$ and $D$ are the Reynolds number and the deformation parameter (see Eq. (4)), respectively. From the maximum value of the similarity solution of the deformation $\left|x_{\mathrm{s}}\right|_{\max } \sim 0.2$ (Sekiya et al, 2003), Equation (11) is rewritten as $D<<5$. Figure 7 shows the possible ranges of the dimensionless parameters, $D$ and $R e$ for various values of nebular shock velocity $v_{\mathrm{s}}$ and pre-shock nebular gas 


\begin{tabular}{|c|c|c|c|c|c|c|c|c|c|c|c|c|}
\hline $\mathrm{v}_{\mathrm{S}}\left[\mathrm{km} \mathrm{s}^{-1}\right]$ & 5 & 6 & 7 & 8 & 9 & 10 & 12 & 14 & 16 & 18 & 20 & 25 \\
\hline \multicolumn{13}{|c|}{$\log \left(\rho_{\mathrm{g} 0}\left[\mathrm{~kg} \mathrm{~m}^{-3}\right]\right.$} \\
\hline-5.5 & _- & & & & & & & & & & & \\
\hline-5.75 & - & $\begin{array}{l}0.08 \\
0.22 \\
0.05 \\
0.06\end{array}$ & $\begin{array}{l}0.17 \\
0.46 \\
0.10 \\
0.12\end{array}$ & $\begin{array}{l}0.31 \\
0.82 \\
0.18 \\
0.21\end{array}$ & $\begin{array}{l}0.50 \\
1 \\
0.29 \\
0.33\end{array}$ & $\begin{array}{l}0.75 \\
1.98 \\
0.44 \\
0.50\end{array}$ & + & & $\begin{array}{c}\operatorname{Re}(\eta=0.13) \\
\operatorname{Re}(\eta=0.08) \\
\operatorname{Re}(\eta=0.17) \\
\mathrm{D}\end{array}$ & & & \\
\hline-6.0 & - & - & $\begin{array}{l}0.09 \\
0.25 \\
0.06 \\
0.06\end{array}$ & $\begin{array}{l}0.17 \\
0.46 \\
0.10 \\
0.11\end{array}$ & $\begin{array}{l}0.28 \\
0.73 \\
0.16 \\
0.18\end{array}$ & $\begin{array}{l}0.42 \\
1.10 \\
0.24 \\
0.28\end{array}$ & $\begin{array}{l}0.81 \\
2.14 \\
0.47 \\
0.54\end{array}$ & + & & & & \\
\hline-6.25 & & - & $\triangle$ & $\triangle$ & $\begin{array}{l}0.10 \\
0.25 \\
0.06 \\
0.06\end{array}$ & $\begin{array}{l}0.16 \\
0.41 \\
0.09 \\
0.10\end{array}$ & $\begin{array}{l}0.23 \\
0.61 \\
0.14 \\
0.15\end{array}$ & + & & & & \\
\hline-6.5 & & & - & $\triangle$ & $\begin{array}{l}0.09 \\
0.23 \\
0.05 \\
0.06\end{array}$ & $\begin{array}{l}0.13 \\
0.34 \\
0.08 \\
0.09\end{array}$ & $\begin{array}{l}0.25 \\
0.66 \\
0.15 \\
0.17 \\
\end{array}$ & $\begin{array}{l}0.41 \\
1.08 \\
0.24 \\
0.27\end{array}$ & + & & & \\
\hline-6.75 & & & & - & $\triangle$ & $\begin{array}{l}0.07 \\
0.19 \\
0.04 \\
0.05\end{array}$ & $\begin{array}{l}0.14 \\
0.37 \\
0.08 \\
0.09\end{array}$ & $\begin{array}{l}0.22 \\
0.59 \\
0.13 \\
0.15\end{array}$ & + & & & \\
\hline-7.0 & & & & & - & $\triangle$ & $\begin{array}{l}0.08 \\
0.21 \\
0.05 \\
0.05\end{array}$ & $\begin{array}{l}0.12 \\
0.33 \\
0.07 \\
0.08 \\
\end{array}$ & \begin{tabular}{l|}
0.16 \\
0.43 \\
0.10 \\
0.11 \\
\end{tabular} & & & \\
\hline-7.25 & & & & & & - & $\begin{array}{l}0.04 \\
0.12 \\
0.03 \\
0.03\end{array}$ & $\begin{array}{l}0.07 \\
0.19 \\
0.04 \\
0.05\end{array}$ & $\begin{array}{l}0.09 \\
0.24 \\
0.05 \\
0.06\end{array}$ & & & \\
\hline-7.5 & & & & & & - & - & $\begin{array}{l}0.04 \\
0.11 \\
0.02 \\
0.03 \\
\end{array}$ & $\begin{array}{l}0.05 \\
0.13 \\
0.03 \\
0.03 \\
\end{array}$ & $\begin{array}{l}0.04 \\
0.11 \\
0.02 \\
0.03 \\
\end{array}$ & + & \\
\hline-7.75 & & & & & & & - & - & $\begin{array}{l}0.03 \\
0.08 \\
0.02 \\
0.02\end{array}$ & $\begin{array}{l}0.02 \\
0.06 \\
0.01 \\
0.02\end{array}$ & $\begin{array}{l}0.02 \\
0.06 \\
0.01 \\
0.02\end{array}$ & \\
\hline-8.0 & & & & & & & & - & - & - & $\begin{array}{l}0.01 \\
0.03 \\
0.01 \\
0.01\end{array}$ & \\
\hline-8.25 & & & & & & & & & - & - & - & \\
\hline-8.5 & & & & & & & & & & & & _- \\
\hline $\mathrm{v}_{\mathrm{S}}\left[\mathrm{km} \mathrm{s}^{-1}\right]$ & 5 & 6 & 7 & 8 & 9 & 10 & 12 & 14 & 16 & 18 & 20 & 25 \\
\hline
\end{tabular}

Fig. 9. Same as Fig. 7 except for $r_{\mathrm{s} 0}=0.17 \mathrm{~mm}$.

density $\rho_{\mathrm{g} 0}$. These values are obtained using the possible range of $p_{\mathrm{fm}}$ in Fig. 10 and $\eta$, and typical values of $r_{\mathrm{s} 0}, T_{\mathrm{s}}$ and $\rho_{\mathrm{s}}$. For the typical parameters considered in this paper $\left(p_{\mathrm{fm}}=490 \mathrm{~N} \mathrm{~m}^{-2}\right)$, we have $D=0.37$ and $R e=0.97$. So the flow may become slightly nonlinear, but the difference from the linear solution would not be so large. The limitation of $R e$ given by Eq. (10) could be rewritten as

$$
p_{\mathrm{fm}}<\frac{9 \eta^{2}}{\rho_{\mathrm{s}} r_{\mathrm{s} 0}^{2}} .
$$

For example, we have $p_{\text {fm }} \lesssim 500 \mathrm{~N} \mathrm{~m}^{-2}$ using the typical value of $\eta, \rho_{\mathrm{s}}$ and $r_{\mathrm{s} 0}$. We also show the cases with $r_{\mathrm{s} 0}=0.17$ and $0.42 \mathrm{~mm}$ in Figs. 8 and 9. As seen in these illustrations, the value of $D$ is always lower than the critical value. Although the upper-limit of the possible range of $R e$ exceeds the critical value in some cases in these figures, Eq. (12) is satisfied for amount of the cases of the nebular gas density and shock wave velocity. Especially, for nebular gas density equal to or less than that at $3 \mathrm{AU}$ of the minimum mass solar nebular, i.e. $\log \left(\rho_{\mathrm{g} 0}\left[\mathrm{~kg} \mathrm{~m}^{-3}\right]\right) \leq-7.25$, the linear approximation is good for all possible values of other parameters as long as $r_{\mathrm{s} 0} \lesssim 0.3 \mathrm{~mm}$. The region in the parameter space $\left(\rho_{\mathrm{g} 0}, v_{\mathrm{s}}\right)$ where the linear approximation is valid is reduced considerably for large chondrules, but note again that all physical parameters except $p_{\mathrm{fm}}$ would be known values when we apply our results to the present chondrules. For example, we can pick up chondrules with radius for which applicability of our results is fairly good. The non-linear numerical calculations for $R e>1$ is left for future works.

In consequence, our typical values satisfy the critical conditions and our results obtained in Section 2.3 are fairly valid. And also, although the properties of the nebular shock wave (i.e. $p_{\text {fm }}$ ) contain a large uncertainty, our calculations are applicable to the wide range of the nebular shock properties.

\section{Conclusions}

We have calculated the deformation and internal flow of the molten silicate sphere moving in the shocked nebular gas using the analytic solution by Sekiya et al. (2003). We obtained following results. (1) Circular flow is driven in the molten sphere. Due to this circular motion, inside of the particle is well mixed within a short period of time. The time scale of the homogenization is less than $4 \mathrm{sec}$, typically $0.1 \mathrm{sec}$. As a consequence, the heterogeneity in the precursor particle, if present, is expected to be homogenized efficiently. (2) The deformation of the particle is of the order of $10 \%$ of the original radius at most for a mm-sized chondruleprecursor molten particle. But the degree of deformation 


\begin{tabular}{|c|c|c|c|c|c|c|c|c|c|c|c|c|}
\hline$v\left[\mathrm{~km} \mathrm{~s}^{-1}\right]$ & 5 & 6 & 7 & 8 & 9 & 10 & 12 & 14 & 16 & 18 & 20 & 25 \\
\hline \multicolumn{13}{|c|}{$\log \left(\rho_{\mathrm{g} 0}\left[\mathrm{~kg} \mathrm{~m}^{-3}\right]\right.$} \\
\hline-5.5 & - & $\begin{array}{c}1.62 \mathrm{E}-05 \\
3.85 \\
2.41 \mathrm{E}+02 \\
\end{array}$ & & & & & & & $\begin{array}{l}\rho_{\mathrm{g}} \\
v_{\text {rel }} \\
p_{\mathrm{fm}}\end{array}$ & $\begin{array}{l}{\left[\mathrm{kg} \mathrm{m}^{-3}\right]} \\
{\left[\mathrm{km} \mathrm{s}^{-1}\right]} \\
{\left[\mathrm{N} \mathrm{m}^{-2}\right]}\end{array}$ & & \\
\hline-5.75 & - & $\begin{array}{c}9.14 \mathrm{E}-06 \\
3.44 \\
1.08 \mathrm{E}+02\end{array}$ & $\begin{array}{c}9.98 \mathrm{E}-06 \\
5.28 \\
2.78 \mathrm{E}+02\end{array}$ & $\begin{array}{c}1.30 \mathrm{E}-05 \\
6.2 \\
5.00 \mathrm{E}+02\end{array}$ & $\begin{array}{c}1.60 \mathrm{E}-05 \\
7.1 \\
8.09 \mathrm{E}+02\end{array}$ & $\begin{array}{c}1.92 \mathrm{E}-05 \\
7.99 \\
1.23 \mathrm{E}+03\end{array}$ & $\begin{array}{c}2.61 \mathrm{E}-05 \\
9.75 \\
2.48 \mathrm{E}+03\end{array}$ & + & & & & \\
\hline-6.0 & - & - & $\begin{array}{c}5.67 \mathrm{E}-06 \\
5.16 \\
1.51 \mathrm{E}+02\end{array}$ & $\begin{array}{c}7.39 \mathrm{E}-06 \\
6.14 \\
2.79 \mathrm{E}+02\end{array}$ & $\begin{array}{c}9.05 \mathrm{E}-06 \\
7.06 \\
4.51 \mathrm{E}+02\end{array}$ & $\begin{array}{c}1.08 \mathrm{E}-05 \\
7.96 \\
6.81 \mathrm{E}+02\end{array}$ & $\begin{array}{c}1.44 \mathrm{E}-05 \\
9.71 \\
1.36 \mathrm{E}+03\end{array}$ & + & & & & $\frac{\pi}{0}$ \\
\hline-6.25 & & - & $\triangle$ & $\begin{array}{c}4.24 \mathrm{E}-06 \\
6.03 \\
1.54 \mathrm{E}+02\end{array}$ & $\begin{array}{c}5.14 \mathrm{E}-06 \\
7.00 \\
2.52 \mathrm{E}+02\end{array}$ & $\begin{array}{c}6.06 \mathrm{E}-06 \\
7.91 \\
3.79 \mathrm{E}+02\end{array}$ & $\begin{array}{c}7.96 \mathrm{E}-06 \\
9.68 \\
7.46 \mathrm{E}+02\end{array}$ & + & & & & $\frac{7}{0}$ \\
\hline-6.5 & & & - & $\triangle$ & $\begin{array}{c}2.96 \mathrm{E}-06 \\
6.88 \\
1.41 \mathrm{E}+02\end{array}$ & $\begin{array}{c}3.44 \mathrm{E}-06 \\
7.85 \\
2.12 \mathrm{E}+02\end{array}$ & $\begin{array}{c}4.42 \mathrm{E}-06 \\
9.65 \\
4.11 \mathrm{E}+02\end{array}$ & $\begin{array}{c}5.37 \mathrm{E}-06 \\
11.4 \\
6.96 \mathrm{E}+02\end{array}$ & + & & & $\frac{\overline{0}}{\pi}$ \\
\hline-6.75 & & & & _- & $\triangle$ & $\begin{array}{c}2.00 \mathrm{E}-06 \\
7.73 \\
1.19 \mathrm{E}+02\end{array}$ & $\begin{array}{c}2.48 \mathrm{E}-06 \\
9.61 \\
2.29 \mathrm{E}+02\end{array}$ & $\begin{array}{c}2.93 \mathrm{E}-06 \\
11.4 \\
3.78 \mathrm{E}+02\end{array}$ & + & & & $\frac{1}{\pi}$ \\
\hline-7.0 & & & & & - & $\triangle$ & $\begin{array}{c}1.42 \mathrm{E}-06 \\
9 \\
1.29 \mathrm{E}+02\end{array}$ & $\begin{array}{c}1.62 \mathrm{E}-06 \\
11.3 \\
2.08 \mathrm{E}+02\end{array}$ & $\begin{array}{c}1.65 \mathrm{E}-06 \\
13.1 \\
2.81 \mathrm{E}+02\end{array}$ & + & & $\frac{1}{0}$ \\
\hline-7.25 & & & & & & - & $\begin{array}{c}8.72 \mathrm{E}-07 \\
9.28 \\
7.52 \mathrm{E}+01\end{array}$ & $\begin{array}{c}9.20 \mathrm{E}-07 \\
11.3 \\
1.17 \mathrm{E}+02\end{array}$ & $\begin{array}{c}8.91 \mathrm{E}-07 \\
13 \\
1.51 \mathrm{E}+02\end{array}$ & + & & $\frac{0}{3}$ \\
\hline-7.5 & & & & & & - & - & $\begin{array}{c}5.57 \mathrm{E}-07 \\
11.1 \\
6.85 \mathrm{E}+01\end{array}$ & $\begin{array}{c}4.99 \mathrm{E}-07 \\
13.0 \\
8.41 \mathrm{E}+01\end{array}$ & $\begin{array}{c}2.99 \mathrm{E}-07 \\
14.8 \\
6.50 \mathrm{E}+01\end{array}$ & + & $\frac{\overline{0}}{\frac{\pi}{2}}$ \\
\hline-7.75 & & & & & & & - & - & $\begin{array}{c}3.13 \mathrm{E}-07 \\
12.7 \\
5.08 \mathrm{E}+01\end{array}$ & $\begin{array}{c}1.68 \mathrm{E}-07 \\
14.7 \\
3.61 \mathrm{E}+01\end{array}$ & $\begin{array}{c}1.36 \mathrm{E}-07 \\
16.4 \\
3.67 \mathrm{E}+01\end{array}$ & 1 \\
\hline-8.0 & & & & & & & & - & $\triangle$ & - & $\begin{array}{c}7.69 \mathrm{E}-08 \\
16.0 \\
1.97 \mathrm{E}+01\end{array}$ & \\
\hline-8.25 & & & & & & & & & & & & \\
\hline-8.5 & & & & & & & & & & & & - \\
\hline$v\left[\mathrm{~km} \mathrm{~s}^{-1}\right]$ & 5 & 6 & 7 & 8 & 9 & 10 & 12 & 14 & 16 & 18 & 20 & 25 \\
\hline
\end{tabular}

Fig. 10. A variety of physical values with a variety of chondrule forming shock waves. Listed in each cell are the density of shocked nebular gas $\rho_{\mathrm{g}}$ (upper), the relative velocity $v_{\text {rel }}$ (middle), and $p_{\text {fm }}$ (lower, shaded), respectively, at the moment when the particle is completely melted calculated by the shock wave heating model by Iida et al. (2001). The initial radius of the particle is assumed to be $r_{\mathrm{s} 0}=0.3 \mathrm{~mm}$. Bold line shows the upper limit of pre-shock nebular gas mass density (see Subsection 2.2) and dotted line indicates the upper limit of the shock velocity which is assumed to be the Keplerian velocity at the Asteroid region. The "+" symbol denotes the condition with which the particle evaporates completely, and "-" symbol represents the condition with which the temperature of the particle does not reach the melting temperature. The " $\triangle$ " symbol denotes the condition with which the temperature of the particle reaches the melting temperature but the particle is not completely melted. If the shock velocity is smaller than 6 $\mathrm{km} \mathrm{s}^{-1}$, the particle is not heated enough to melt.

decreases considerably as the relative velocity between the sphere and the gas decreases due to the gas drag. When the molten particle re-solidifies, the deformation of the particle may be $10^{-2}$ or less of its radius and it seems difficult to detect this deformation in observed chondrules.

\section{Appendix A.}

Here, we briefly summarize the basic equations and results of Sekiya et al. (2003), which solved the flow in the liquid sphere and deformation of its surface moving with a hypersonic velocity in a rarefied gas. The model of liquid sphere is given in Subsection 2.3. It is assumed that the liquid sphere is isothermal, symmetrical with respect to the z-axis, and has no azimuthal velocity, and that the internal flow is steady.

Equations representing boundary conditions on the surface of liquid sphere are given by

$$
\boldsymbol{v} \cdot \boldsymbol{n}=0,
$$

where $\boldsymbol{v}=v_{\mathrm{r}} \boldsymbol{e}_{\mathrm{r}}+v_{\theta} \boldsymbol{e}_{\theta}$ is the fluid velocity in the sphere, $\boldsymbol{e}_{\mathrm{r}}$ and $\boldsymbol{e}_{\theta}$ are unit vectors for $r$ and $\theta$ directions, respectively, and $\boldsymbol{n}=n_{\mathrm{r}} \boldsymbol{e}_{\mathrm{r}}+n_{\theta} \boldsymbol{e}_{\theta}$ is the normal vector of sphere, and

$$
\begin{aligned}
-\left(\boldsymbol{n} \cdot \boldsymbol{e}_{\mathrm{z}}\right) p_{\mathrm{fm}} \mathrm{H}[(\pi / 2)-\theta] \boldsymbol{e}_{\mathrm{z}}= & n_{\mathrm{r}} \sigma_{\mathrm{in}, \mathrm{rr}} \boldsymbol{e}_{\mathrm{r}}+n_{\theta} \sigma_{\mathrm{in}, \mathrm{r} \theta} \boldsymbol{e}_{\mathrm{r}} \\
& +n_{\mathrm{r}} \sigma_{\mathrm{in}, \theta \mathrm{r}} \boldsymbol{e}_{\theta}+n_{\theta} \sigma_{\mathrm{in}, \theta \theta} \boldsymbol{e}_{\theta} \\
& +T_{\mathrm{s}} \cdot\left(\frac{1}{R_{\theta}}+\frac{1}{R_{\phi}}\right) \boldsymbol{n},
\end{aligned}
$$

where the function $\mathrm{H}[(\pi / 2)-\theta]$ is the step function, whose values are unity and zero for $\theta<\pi / 2$ and $\theta \geq \pi / 2$, respectively. The stress tensor is given by

$$
\begin{gathered}
\sigma_{\mathrm{in}, \mathrm{rr}}=-p+2 \eta \frac{\partial v_{\mathrm{r}}}{\partial r}, \\
\sigma_{\mathrm{in}, \theta \theta}=-p+2 \eta\left(\frac{1}{r} \frac{\partial v_{\theta}}{\partial \theta}+\frac{v_{\mathrm{r}}}{r}\right),
\end{gathered}
$$

and

$$
\sigma_{\mathrm{in}, \mathrm{r} \theta}=\sigma_{\mathrm{in}, \theta \mathrm{r}}=\eta\left(\frac{1}{r} \frac{\partial v_{\mathrm{r}}}{\partial \theta}+\frac{\partial v_{\theta}}{\partial r}-\frac{v_{\theta}}{r}\right),
$$

where $p$ is the pressure. The principal radii of curvature of the sphere, $R_{\theta}$ and $R_{\phi}$, are given by

$$
\frac{1}{R_{\theta}}=\frac{\left|\frac{\partial \boldsymbol{n}}{\partial \theta}\right|}{\left|\frac{\partial \boldsymbol{r}_{\mathrm{s}}}{\partial \theta}\right|}=\frac{r_{\mathrm{s}}^{2}-r_{\mathrm{s}} \frac{d^{2} r_{\mathrm{s}}}{d \theta^{2}}+2\left(\frac{d r_{\mathrm{s}}}{d \theta}\right)^{2}}{\left[r_{\mathrm{s}}^{2}+\left(\frac{d r_{\mathrm{s}}}{d \theta}\right)^{2}\right]^{3 / 2}},
$$




\begin{tabular}{|c|c|c|c|c|c|c|c|c|c|c|c|c|}
\hline$v\left[\mathrm{~km} \mathrm{~s}^{-1}\right]$ & 5 & 6 & 7 & 8 & 9 & 10 & 12 & 14 & 16 & 18 & 20 & s5 \\
\hline \multicolumn{13}{|c|}{$\log \left(\rho_{\mathrm{g} 0}\left[\mathrm{~kg} \mathrm{~m}^{-3}\right]\right.$} \\
\hline-5.5 & & & & & & & & & $\begin{array}{l}\rho_{\mathrm{g}} \\
v_{\text {rel }} \\
p_{\mathrm{fm}}\end{array}$ & 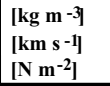 & & \\
\hline-5.75 & - & $\triangle$ & $\begin{array}{c}1.02 \mathrm{E}-05 \\
5.27 \\
2.83 \mathrm{E}+02 \\
\end{array}$ & $\begin{array}{c}1.33 \mathrm{E}-05 \\
6.19 \\
5.10 \mathrm{E}+02 \\
\end{array}$ & $\begin{array}{c}1.65 \mathrm{E}-05 \\
7.10 \\
8.29 \mathrm{E}+02 \\
\end{array}$ & $\begin{array}{c}1.98 \mathrm{E}-05 \\
7.99 \\
1.26 \mathrm{E}+03\end{array}$ & $\begin{array}{c}2.84 \mathrm{E}-05 \\
9.74 \\
2.60 \mathrm{E}+03 \\
\end{array}$ & + & & & & \\
\hline-6.0 & & - & $\begin{array}{c}5.78 \mathrm{E}-06 \\
5.15 \\
1.53 \mathrm{E}+02 \\
\end{array}$ & $\begin{array}{c}7.57 \mathrm{E}-06 \\
6.13 \\
2.85 \mathrm{E}+02 \\
\end{array}$ & $\begin{array}{c}9.29 \mathrm{E}-06 \\
7.05 \\
4.62 \mathrm{E}+02\end{array}$ & $\begin{array}{c}1.11 \mathrm{E}-05 \\
7.95 \\
7.01 \mathrm{E}+02 \\
\end{array}$ & $\begin{array}{c}1.51 \mathrm{E}-05 \\
9.71 \\
1.42 \mathrm{E}+03\end{array}$ & + & & & & $=\frac{0}{00}$ \\
\hline-6.25 & & & $\triangle$ & $\begin{array}{c}4.37 \mathrm{E}-06 \\
6.01 \\
1.58 \mathrm{E}+02 \\
\end{array}$ & $\begin{array}{c}5.28 \mathrm{E}-06 \\
6.99 \\
2.58 \mathrm{E}+02 \\
\end{array}$ & $\begin{array}{c}6.24 \mathrm{E}-06 \\
7.91 \\
3.90 \mathrm{E}+02 \\
\end{array}$ & $\begin{array}{c}8.31 \mathrm{E}-06 \\
9.68 \\
7.79 \mathrm{E}+02 \\
\end{array}$ & + & & & & $\frac{0}{0}$ \\
\hline-6.5 & & & & $\triangle$ & $\begin{array}{c}3.07 \mathrm{E}-06 \\
6.87 \\
1.45 \mathrm{E}+02 \\
\end{array}$ & $\begin{array}{c}3.55 \mathrm{e}--6 \\
7.85 \\
2.19 \mathrm{E}+02\end{array}$ & $\begin{array}{c}4.60 \mathrm{E}-06 \\
9.65 \\
4.28 \mathrm{E}+02 \\
\end{array}$ & $\begin{array}{c}5.70 \mathrm{E}-06 \\
11.4 \\
7.40 \mathrm{E}+02 \\
\end{array}$ & + & & & $\mid \begin{array}{l}\tilde{2} \\
0 \\
0\end{array}$ \\
\hline-6.75 & & & & & $\triangle$ & $\begin{array}{c}2.08 \mathrm{E}-06 \\
7.72 \\
1.24 \mathrm{E}+02 \\
\end{array}$ & $\begin{array}{c}2.58 \mathrm{E}-06 \\
9.60 \\
2.38 \mathrm{E}+02 \\
\end{array}$ & $\begin{array}{c}3.09 \mathrm{E}-06 \\
11.4 \\
3.99 \mathrm{E}+02 \\
\end{array}$ & + & & & 吾 \\
\hline-7.0 & & & & & & $\triangle$ & $\begin{array}{c}1.48 \mathrm{E}-06 \\
9.53 \\
1.34 \mathrm{E}+02 \\
\end{array}$ & $\begin{array}{c}1.70 \mathrm{E}-06 \\
11.3 \\
2.19 \mathrm{E}+02 \\
\end{array}$ & $\begin{array}{c}1.78 \mathrm{E}-06 \\
13.1 \\
3.04 \mathrm{E}+02 \\
\end{array}$ & + & & $\frac{0}{0}$ \\
\hline-7.25 & & & & & & - & $\begin{array}{c}9.35 \mathrm{E}-07 \\
9.30 \\
8.09 \mathrm{E}+01\end{array}$ & $\begin{array}{c}9.66 \mathrm{E}-07 \\
11.3 \\
1.23 \mathrm{E}+02\end{array}$ & $\begin{array}{c}9.53 \mathrm{E}-07 \\
13.0 \\
1.62 \mathrm{E}+02\end{array}$ & + & & $\frac{\pi}{\pi}$ \\
\hline-7.5 & & & & & & & - & $\begin{array}{c}5.97 \mathrm{E}-07 \\
11.1 \\
7.36 \mathrm{E}+01 \\
\end{array}$ & $\begin{array}{c}5.32 \mathrm{E}-07 \\
13.0 \\
8.96 \mathrm{E}+01 \\
\end{array}$ & $\begin{array}{c}3.00 \mathrm{E}-07 \\
14.8 \\
6.55 \mathrm{E}+01 \\
\end{array}$ & + & $\frac{\pi}{2}$ \\
\hline-7.75 & & & & & & & - & $\begin{array}{c}9.97 \mathrm{E}-07 \\
9.06 \\
8.19 \mathrm{E}+01 \\
\end{array}$ & $\begin{array}{c}3.38 \mathrm{E}-07 \\
12.8 \\
5.53 \mathrm{E}+01\end{array}$ & $\begin{array}{c}1.69 \mathrm{E}-07 \\
14.7 \\
3.63 \mathrm{E}+01 \\
\end{array}$ & $\begin{array}{c}1.36-7 \\
16.4 \\
3.67 \mathrm{E}+01 \\
\end{array}$ & \\
\hline-8.0 & & & & & & & & . & $\begin{array}{c}5.14 \mathrm{E}-07 \\
11.5 \\
6.84 \mathrm{E}+01 \\
\end{array}$ & $5.00 \pi \cdot 21$ & $\begin{array}{c}7.72 \mathrm{E}-08 \\
16.1 \\
1.99 \mathrm{E}+01 \\
\end{array}$ & \\
\hline-8.25 & & & & & & & & & & & & \\
\hline-8.5 & & & & & & & & & & & & - \\
\hline$v\left[\mathrm{~km} \mathrm{~s}^{-}\right]$ & 5 & 6 & 7 & 8 & 9 & 10 & 12 & 14 & 16 & 18 & 20 & 25 \\
\hline
\end{tabular}

Fig. 11. Same as Fig. 10 except for $r_{\mathrm{s} 0}=0.42 \mathrm{~mm}$.

and

$$
\frac{1}{R_{\phi}}=\frac{\left|\frac{\partial \boldsymbol{n}}{\partial \phi}\right|}{\left|\frac{\partial \boldsymbol{r}_{\mathrm{s}}}{\partial \phi}\right|}=\frac{1-\frac{1}{r_{\mathrm{s}}} \frac{d r_{\mathrm{s}}}{d \theta} \cot \theta}{\left[r_{\mathrm{s}}^{2}+\left(\frac{d r_{s}}{d \theta}\right)^{2}\right]^{1 / 2}}
$$

where $\boldsymbol{r}_{\mathrm{s}}$ is the position vector of the surface.

The continuity and Navier-Stokes equations of the steady flow (i.e., $\partial / \partial t=0$ ) in the sphere are written (e.g., Landau and Lifshitz, 1959)

$$
r \frac{\partial v_{\mathrm{r}}}{\partial r}+2 v_{\mathrm{r}}+\frac{\partial v_{\theta}}{\partial \theta}+v_{\theta} \cot \theta=0
$$

$$
\begin{aligned}
v_{\mathrm{r}} \frac{\partial v_{\mathrm{r}}}{\partial r}+\frac{v_{\theta}}{r} \frac{\partial v_{\mathrm{r}}}{\partial \theta}-\frac{v_{\theta}^{2}}{r}= & g \cos \theta-\frac{1}{\rho} \frac{\partial p}{\partial r}+v\left[\frac{1}{r} \frac{\partial^{2}\left(r v_{\mathrm{r}}\right)}{\partial r^{2}}+\frac{1}{r^{2}} \frac{\partial^{2} v_{\mathrm{r}}}{\partial \theta^{2}}\right. \\
& \left.+\frac{\cot \theta}{r^{2}} \frac{\partial v_{\mathrm{r}}}{\partial \theta}-\frac{2}{r^{2}} \frac{\partial v_{\theta}}{\partial \theta}-\frac{2 v_{\mathrm{r}}}{r^{2}}-\frac{2 \cot \theta}{r^{2}} v_{\theta}\right],
\end{aligned}
$$

(A.9) and

$$
\begin{aligned}
v_{\mathrm{r}} \frac{\partial v_{\theta}}{\partial r}+\frac{v_{\theta}}{r} \frac{\partial v_{\theta}}{\partial \theta}+\frac{v_{\mathrm{r}} v_{\theta}}{r}= & -g \sin \theta-\frac{1}{\rho r} \frac{\partial p}{\partial \theta}+v[1 \\
& +\frac{1}{r^{2}} \frac{\partial^{2} v_{\theta}}{\partial \theta^{2}}+\frac{\cot \theta}{r^{2}} \frac{\partial v_{\theta}}{\partial \theta} \\
& \left.+\frac{2}{r^{2}} \frac{\partial v_{\mathrm{r}}}{\partial \theta}-\frac{v_{\theta}}{r^{2} \sin \theta}\right] .
\end{aligned}
$$

where $v=\eta / \rho_{s}$ is the kinematic viscosity of the liquid.
For an unperturbed state, fluid elements in the sphere have no velocity and the surface of the sphere is completely spherical. We assume that the deformation of the surface is small and we omit higher order terms. We also assume that nonlinear terms in the LHS of Eqs. (A.9) and (A.10) can be omitted. Then, we can obtain the velocity field of the internal flow and surface deformation from the equations, using the Legendre transformation of each variables $r_{\mathrm{s}}, v_{\mathrm{r}}$, and $v_{\theta}$. The solutions are as follows:

$$
v_{\mathrm{r} 1}=v_{\text {scale }} u(r, \theta)
$$

$$
\begin{gathered}
v_{\theta 1}=v_{\text {scale }} \frac{\partial w(r, \theta)}{\partial \theta} \\
p_{1}=p_{\mathrm{fm} 1} \Psi(r, \theta)
\end{gathered}
$$

$$
r_{\mathrm{s} 1}=D r_{\mathrm{s} 0} x_{\mathrm{s}}(\theta)
$$

where

$$
\begin{aligned}
u(r, \theta)= & \sum_{n=1}^{\infty} \frac{n(n+1)}{4(2 n+1)} a_{n}\left(\frac{r}{r_{\mathrm{s} 0}}\right)^{n-1} \\
& \cdot\left[1-\left(\frac{r}{r_{\mathrm{s} 0}}\right)^{2}\right] \mathrm{P}_{n}(\cos \theta)
\end{aligned}
$$




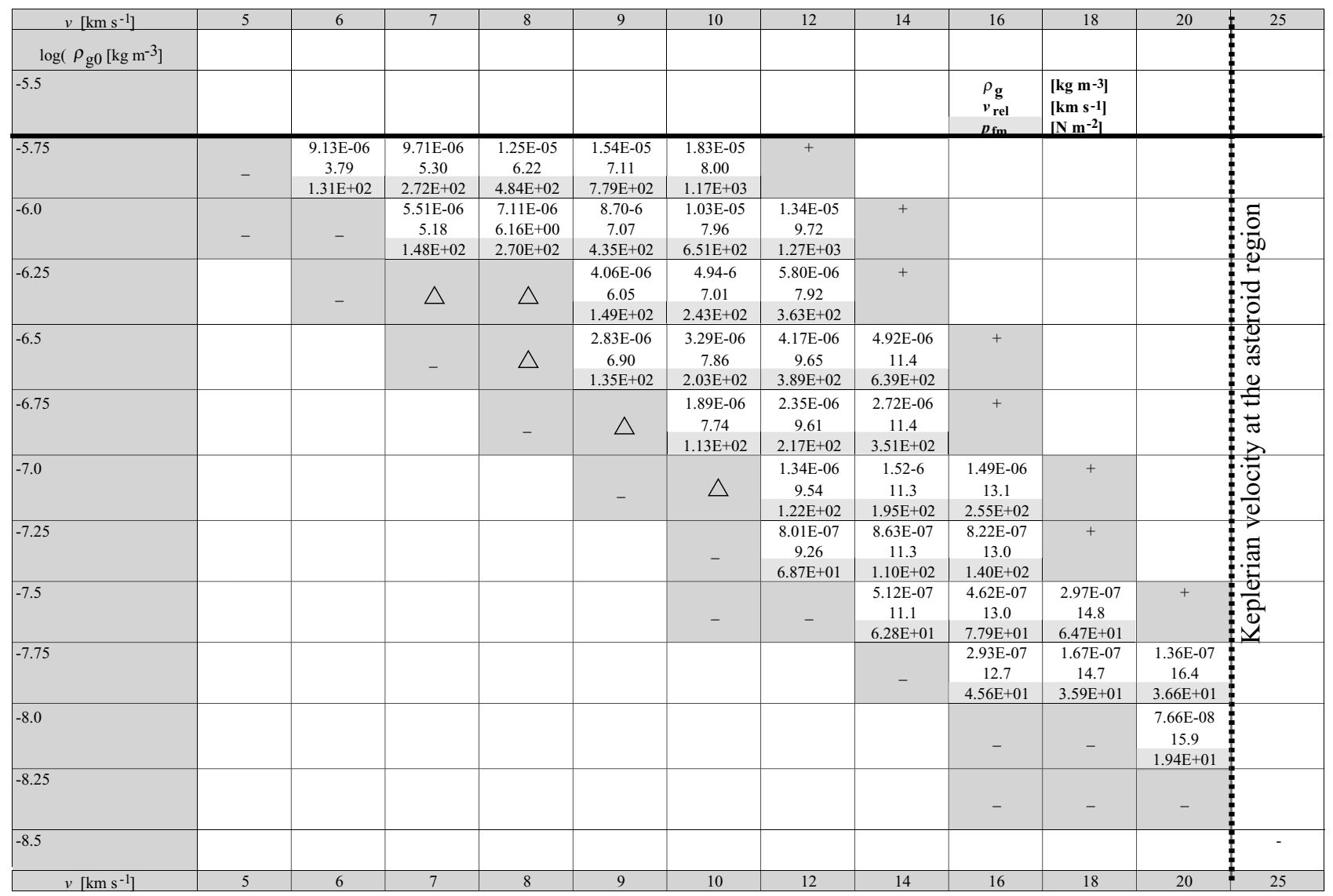

Fig. 12. Same as Fig. 10 except for $r_{\mathrm{s} 0}=0.17 \mathrm{~mm}$.

$$
\begin{aligned}
w(r, \theta)= & \sum_{n=1}^{\infty} \frac{a_{n}}{4(2 n+1)}\left[(n+1)\left(\frac{r}{r_{\mathrm{s} 0}}\right)^{n-1}\right. \\
& \left.-(n+3)\left(\frac{r}{r_{\mathrm{s} 0}}\right)^{n+1}\right]\left[\mathrm{P}_{n}(\cos \theta)-1\right],
\end{aligned}
$$

$$
\begin{aligned}
\Psi(r, \theta)= & \frac{1}{6}+\frac{3}{4}\left(\frac{r}{r_{\mathrm{s} 0}}\right) \cos \theta-\sum_{n=1}^{\infty} \\
& \cdot \frac{(n+1)(2 n+3)}{2(2 n+1)} a_{n}\left(\frac{r}{r_{\mathrm{s} 0}}\right)^{n} \mathrm{P}_{n}(\cos \theta),
\end{aligned}
$$

$$
\begin{gathered}
x_{\mathrm{s}}(\theta)=\left[\sum_{m=1}^{\infty} \frac{(-1)^{m}(7 m+6)(2 m+1) ! !}{2 m(2 m+3)(4 m+3)(2 m) ! !} a_{2 m+1}\right] \cos \theta+\sum_{n=2}^{\infty} \\
\frac{1}{2-n(n+1)}\left[1+\frac{3(n+1)}{2(2 n+1)}\right] a_{n} \mathrm{P}_{n}(\cos \theta), \\
a_{0}=\frac{1}{6}, \quad a_{1}=\frac{3}{8}, \quad a_{2}=\frac{1}{3}, \quad a_{3}=\frac{7}{48}, \\
a_{n}=0 \text { for even } n \geq 4,
\end{gathered}
$$

and

$$
a_{n}=\frac{(-1)^{(n+1 / 2)}(2 n+1)(n-4) ! !}{(n+3) ! !} \text { for odd } n \geq 5 .
$$

The function $\mathrm{P}_{n}(\cos \theta)$ is the Legendre function and variables accompanied by subscript 0 and 1 are unperturbed and perturbed quantities, respectively.

\section{Appendix B.}

Here we show a variety of the gas density, the relative velocity, and the momentum flux with a variety of chondruleforming shock waves. In a cell in Figs. 10, 11 and 12, the density of shocked nebular gas $\rho_{\mathrm{g}}$ (upper), the relative velocity $v_{\text {rel }}$ (middle), and $p_{\text {fm (lower, shaded), at the moment }}$ when the particle is completely melted, are listed. The initial radius of the particle for Figs. 10,11 and 12 is assumed to be $r_{\mathrm{s} 0}=0.3 \mathrm{~mm}, 0.17 \mathrm{~mm}$ and $0.42 \mathrm{~mm}$, respectively. These values are calculated using the shock wave heating model by Iida et al. (2001). Bold line corresponds to the upper limit of the pre-shock nebular gas mass density (see Subsection 2.2). Dotted line indicates the upper limit of the shock velocity which is assumed to be the Keplerian velocity at the Asteroid region. The maximum and minimum values of $p_{\mathrm{fm}}$ are attained at $v_{\mathrm{s}}=12 \mathrm{~km} \mathrm{~s}^{-1}$ and $\log \left(\rho_{\mathrm{g} 0}\left[\mathrm{~kg} \mathrm{~m}^{-3}\right]\right)=-5.75$, and $v_{\mathrm{s}}=20 \mathrm{~km} \mathrm{~s}^{-1}$ and $\log \left(\rho_{\mathrm{g} 0}\left[\mathrm{~kg} \mathrm{~m}^{-3}\right]\right)=-8.0$, respectively. If the shock velocity is smaller than $6 \mathrm{~km} \mathrm{~s}^{-1}$, the particle is not heated enough to melt.

Acknowledgments. The authors thank Dr. Hidekazu Tanaka, Dr. Tomoki Nakamura, and Mr. Takeshi Akaki for valuable comments. They also thank Dr. Akira Iida for providing his numerical code. The numerical calculations were performed partly at the Astronomical Data Analysis Center of the National Astronomical Observatory, Japan, and partly at the Center for Computational 
Physics, University of Tsukuba. TN is partially supported by the research grant of the University of Tsukuba and the grant from the Japan Society for the Promotion of Science (No. 14740284).

\section{References}

Boss, A. P., A concise guide to chondrule formation models, in Chondrules and the Protoplanetary Disk, edited by R. H. Hewins, R. H. Jones, and E. R. D. Scott, pp. 257-263, Cambridge Univ. Press, Cambridge, 1996.

Boss, A. P., Possible rapid gas giant planet formation in the solar nebula and other protoplanetary disks, Astrophys. J., 536, L101-L104, 2000.

Boss, A. P. and J. A. Graham, Clumpy disk accretion and chondrule formation, Icarus, 106, 168-178, 1993.

Bottinga, Y. and D. G. Weill, The viscosity of magmatic silicate liquids: A model for calculation, Am. Jour. Sci., 272, 438-475, 1972.

Ciesla, F. J. and L. L. Hood, The nebular shock wave model for chondrule formation: Shock processing in a particle-gas suspension, Icarus, $\mathbf{1 5 8}$ 281-293, 2002.

Clayton, R. N., Oxygen Isotopes in meteorites, Annu. Rev. Earth Planet Sci., 21, 115-149, 1993

Desch, S. J. and H. C. Connolly, A model of the thermal processing of particles in solar nebula shocks: Application to the cooling rates of chondrules, Meteorit. Planet. Sci., 37, 183-207, 2002.

Desch, S. J. and J. N. Cuzzi, The generation of lightning in the solar nebula, Icarus, 143, 87-105, 2000.

Dunn, T., Oxygen diffusion in three silicate melts along the join diopsideanorthite, Geochim. Cosmochim. Acta, 46, 2293-2299, 1982.

Gooding, J. L. and K. Keil, Relative abundances of chondrule primary textual types in ordinary chondrites and their bearing on conditions of chondrule formation, Meteoritics, 16, 17-43, 1981.

Hewins, R. H. and P. M. Radomsky, Temperature conditions for chondrules formation, Meteoritics, 25, 309-318, 1990.

Hiyagon, $\mathrm{H}$., In situ analysis of oxygen isotopes and $\mathrm{Fe} / \mathrm{Mg}$ ratios in olivine using SIMS: Preliminary results for an Allende chondrule, Antarct. Me teorite Res., 10, 249-274, 1997.

Hood, L. L., Thermal processing of chondrule and CAI precursors in planetesimal bow shocks, Meteorit. Planet. Sci., 33, 97-107, 1998.

Hood, L. L. and M. Horanyi, Gas dynamic heating of chondrule precursor grains in the solar nebula, Icarus, 93, 259-269, 1991

Hood, L. L. and M. Horanyi, The nebular shock wave model for chondrule formation: One-dimensional calculations, Icarus, 106, 179-189, 1993.

Hood, L. L. and D. A. Kring, Models for multiple heating mechanisms, in Chondrules and the Protoplanetary Disk, edited by R. H. Hewins, R. H. Jones, and E. R. D. Scott, pp. 265-276, Cambridge Univ. Press, Cambridge, 1996.

Horanyi, M. and S. Robertson, Chondrule formation in lightning discharges; Status of theory and experiment, in Chondrules and the Protoplanetary Disk, edited by R. H. Hewins, R. H. Jones, and E. R. D. Scott, pp. 303 310, Cambridge Univ. Press, Cambridge, 1996.

Iida, A., T. Nakamoto, H. Susa, and Y. Nakagawa, A shock heating model for chondrule formation in a protoplanetary disk, Icarus, 153, 430-450, 2001

Jones, R. H., T. Lee, H. C. Connolly, S. G. Love, and H. Shang, Formation of chondrules and CAIs: Theory vs. observations, in Protostars and Planets $I V$, edited by V. Mannings, A. P. Boss, and S. S. Russell, pp. 927-962, Univ. of Arizona Press, Tucson, 2000a.

Jones, R. H., J. M. Sazton, I. C. Lyon, and G. Turner, Oxygen isotopes in chondrules olivine and isolated olivine grains from the $\mathrm{CO} 3$ chondrite Allan Hills A77307, Meteorit. Planet. Sci., 35, 849-857, 2000 b.

King, T. B., The surface tension and structure of silicate slags, J. Soc. Glass Technol., 35, 241-259, 1951.

Kuebler, K. E. and H. Y. McSween, Sizes and masses of chondrules and
Metal-Troilite grains in ordinary chondrites: Possible implications for nebular sorting, Icarus, 141, 96-106, 1999.

Landau, L. D. and E. M. Lifshitz, Fluid Mechanics, 319 pp., Pergamon, Elmsford., 1959

Liffman, K., The formation of chondrules via ablation, Icarus, 100, 608$620,1992$.

Liffman, K. and M. J. I. Brown, The protostellar jet model of chondrule formation, in Chondrules and the Protoplanetary Disk, edited by R. H. Hewins, R. H. Jones, and E. R. D. Scott, pp. 285-302, Cambridge Univ. Press, Cambridge, 1996.

Miura, H., T. Nakamoto, and H. Susa, A shock wave heating model for chondrule formation: effects of evaporation and gas flows on silicate particles, Icarus, 160, 258-270, 2002.

Podolak, M., D. Prialnik, T. E. Bunch, P. Cassen, and R. Reynolds, Secondary processing of chondrules and refractory inclusions (CAIs) by gasdynamic heating, Icarus, 104, 97-109, 1993.

Ruzmaikina, T. V. and W. H. Ip, Chondrule formation in radiative shock, Icarus, 112, 430-447, 1994.

Sekiya, M. and T. Nakamura, Condition for the formation of the compound chondrules in the solar nebula, Proc. NIPR Symp. Antarct. Meteorites, 9 , 208-217, 1996.

Sekiya, M., M. Uesugi, and T. Nakamoto, Flow in a liquid sphere moving with a hypersonic velocity in a rarefied gas, Progr. Theor. Phys., 109, 717, 2003.

Shu, F. H., H. Shang, and T. Lee, Toward an astrophysical theory of chondrites, Science, 271, 1545-1552, 1996.

Shu, F. H., H. Shang, A. E. Glassgold, and T. Lee, X-rays and fluctuating X-winds from protostars, Science, 277, 1475-1479, 1997.

Shu, F. H., H. Shang, M. Gounelle, A. E. Glassgold, and T. Lee, The origin of chondrules and refractory inclusions in chondritic meteorites, Astrophys. J., 548, 1029-1050, 2001.

Sorby, H., On the structure and origin of meteorites, Nature, 15, 495-498, 1877.

Stacey, F. D., Physics of the earth, third edition, Brookfiled Press, Queensland, Australia, 1992.

Susa, H. and T. Nakamoto, On the maximal size of chondrules in shock wave heating model, Astrophys. J., 564, L57-L60, 2002.

Tanaka, K. K., H. Tanaka, and K. Nakazawa, Shock heating due to accretion of a clumpy cloud onto a protoplanetary disk, Icarus, 134, 137-154, 1998.

Tsuchiyama, A., H. Nagahara, and I. Kushiro, Volatilization of sodium from silicate melt spheres and its application to the formation of chondrules, Geochim. Cosmochim. Acta, 45, 1357-1367, 1981.

Tsuchiyama, A., R. Shigeyoshi, T. Nakano, K. Uesugi, and S. Shirono, Three-dimensional shapes and internal structures of chondrules form the Allende meteorite by X-ray CT: high-speed rotation (abstract), Antarctic Meteorites XXVII, 168-170, National Institute of Polar Research, 2002.

Watanabe, S., Behavior of dust grains in protoplanetary disks with bipolar outflows, Proceedings of the 27-th ISAS Lunar and Planetary Symposium, 83, 1994.

Weidenschilling, S. J., F. Mazari, and L. L. Hood, The origin of chondrules at jovian resonances, Science, 279, 681-684, 1998.

Weisberg, M. K., Barred olivine chondrules in ordinary chondrites, Journal Proc. Lunar Planet. Sci. Conf. 19th, E663-E678, 1987.

Wood, J. A., On the formation of meteoritic chondrules by aerodynamic drag heating in the solar nebula, Earth Planet. Sci. Lett., 70, 11-26, 1984

Wood, J. A., Processing of chondritic and planetary material in spiral density waves in the nebula, Meteoritics Planet. Sci., 31, 641-645, 1996.

M. Uesugi (e-mail: uesugi@geo.kyushu-u.ac.jp), M. Sekiya, and T. Nakamoto 